\title{
Proton Exchange Membrane Fuel Cells Modeling Using Chaos Game Optimization Technique
}

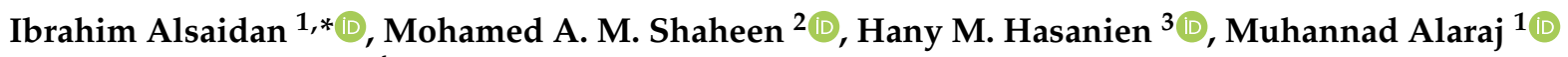 \\ and Abrar S. Alnafisah ${ }^{4}$ \\ 1 Department of Electrical Engineering, College of Engineering, Qassim University, \\ Buraydah 52571, Qassim, Saudi Arabia; Muhannad@qu.edu.sa \\ 2 Electrical Engineering Department, Faculty of Engineering and Technology, Future University in Egypt, \\ Cairo 11835, Egypt; mohamed.shaheen@fue.edu.eg \\ 3 Electrical Power and Machines Department, Faculty of Engineering, Ain Shams University, \\ Cairo 11517, Egypt; hanyhasanien@ieee.org \\ 4 Department of Chemistry, College of Science, Qassim University, Buraydah 52571, Qassim, Saudi Arabia; \\ Alnafisaha@qu.edu.sa \\ * Correspondence: Alsaidan@qu.edu.sa
}

Citation: Alsaidan, I.; Shaheen, M.A.M.; Hasanien, H.M.; Alaraj, M.; Alnafisah, A.S. Proton Exchange Membrane Fuel Cells Modeling Using Chaos Game Optimization Technique. Sustainability 2021, 13, 7911. https:// doi.org/10.3390/su13147911

Academic Editor: Nicu Bizon

Received: 18 April 2021

Accepted: 9 July 2021

Published: 15 July 2021

Publisher's Note: MDPI stays neutral with regard to jurisdictional claims in published maps and institutional affiliations.

Copyright: (c) 2021 by the authors. Licensee MDPI, Basel, Switzerland. This article is an open access article distributed under the terms and conditions of the Creative Commons Attribution (CC BY) license (https:// creativecommons.org/licenses/by/ $4.0 /)$.
Abstract: For the precise simulation performance, the accuracy of fuel cell modeling is important. Therefore, this paper presents a developed optimization method called Chaos Game Optimization Algorithm (CGO). The developed method provides the ability to accurately model the proton exchange membrane fuel cell (PEMFC). The accuracy of the model is tested by comparing the simulation results with the practical measurements of several standard PEMFCs such as Ballard Mark V, AVISTA SR-12.5 kW, and $6 \mathrm{~kW}$ of the Nedstack PS6 stacks. The complexity of the studied problem stems from the nonlinearity of the PEMFC polarization curve that leads to a nonlinear optimization problem, which must be solved to determine the seven PEMFC design variables. The objective function is formulated mathematically as the total error squared between the laboratory measured terminal voltage of PEMFC and the estimated terminal voltage yields from the simulation results using the developed model. The CGO is used to find the best way to fulfill the preset requirements of the objective function. The results of the simulation are tested under different temperature and pressure conditions. Moreover, the results of the proposed CGO simulations are compared with alternative optimization methods showing higher accuracy.

Keywords: laboratory results; optimization techniques; PEMFC modelling; polarization curves; parameters extraction

\section{Introduction}

In addition to the environmental impact of fossil fuels, they are declining and unsustainable sources of energy. For this reason, more focus has been given to develop clean renewable energy resources [1,2]. FCs are among promising energy resources. In FCs, electricity is generated by chemical reactions from chemical energy [3-5]. PEMFC is one of the FCs that have been widely used. The major characteristics and benefits of the PEMFCs are: (1) low operating pressure and temperature, (2) high performance ratio, and (3) no waste materials [6]. The fuel cell temperature requirements vary from 50 to $100^{\circ} \mathrm{C}$ and the output power is between 30 and 60 percent under these temperature operating conditions [6,7]. In [8], a switched reluctance motor powered by the PEMFC's stack is used to optimize the operating performance. The performance is examined in terms of: (1) torque-ampere ratio, (2) torque smoothness, and (3) starting torque. The work in [9] applies an algorithm to a step-up converter in order to improve the performance of PEMFCs. A comprehensive review of the benefits of different design and optimization algorithms for PEMFCs is provided in [10]. In [11], a model is introduced for the PEMFC to save the undesirable 
thermal energy generated during the operation. The model uses the unoccupied capacity of the PEMFC to produce/store hydrogen.

Many researchers have recently drawn attention to the construction of a PEMFC model. A hybrid optimization approach is introduced in [12] for estimating the parameters of the PEMFC. The analysis in this work is performed on a $250 \mathrm{~W}$ stack, NedStack PS6, BCS 500-W, and SR-12 PEM $500 \mathrm{~W}$ fuel cells. To obtain results which are very similar to experimental results, the researchers strive to find a trustworthy PEMFC model with software programs and modeling that reduce substantial time and effort [13]. The PEMFC modeling is an important and promising research field. Both conventional and metaheuristic methods can be used to extract the parameters of the fuel cell. For example, the work in [14] introduces an evaluation of parameters' effects on the FC performance and model validation besides identification of optimal parameters. Taleb [15] presents monitoring of the operation of the PEMFC using a model-based approach. Experimental validation is done to the model using a frequency identification method. Then, time series identification is conducted using a least square method. In [16], a semi-empirical model is proposed based on the data of a three-cell SOFC stack, which predicts the performance of real stacks. The effects of key operation parameters were studied. The generalized reduced gradient technique is introduced in [17]. Moreover, in that context, a large number of complex analysis techniques were implemented to obtain an accurate fuel cell model [18-20].

Traditional optimization methods are unable to achieve sufficient results over a fair period. There are also drawbacks of traditional optimization methods which includes: (i) sensitivity for the initial problem estimate, (ii) reliance on solution exactness on the differential equation solver, and (iii) the possibility of getting trapped in a local solution. The probability of becoming trapped in a local optimal solution increases when dealing with highly nonlinear problems.

To efficiently deal with complex optimization problems, various algorithms have been developed. One of these algorithms is the CGO algorithm, which was introduced by Talatahari, Siamak, and Mahdi Azizi. [21]. The new optimization approach can be chosen to solve various problems in the field of engineering and other areas such as manufacturing applications and scientific models. The key idea of the CGO algorithm consists of some theories of chaos, which consider the construction of fractals according to the chaos game and the fractal problems of self-similarity. The findings have shown the superiority of the CGO in most cases. The theory of chaos shows that a few slight modifications in the initial guess of a complex system led to drastic variations in the conditions of these systems as they depend on the initial conditions.

In this paper, a new application of the CGO algorithm is presented to achieve the optimal PEMFC model design parameters. The objective of this study is to develop a PEMFC theoretical model. The results of the developed model are tested using measurements data provided by practical experiments. The experimentally measured data should yield close results to those found by the theoretical model. Considering that the data provided by the manufacturers are insufficient, and because of the nonlinear properties of the PEMFC as well as the seven design variables, the current-voltage characteristics of the PEMFC must be modeled. Thus, a NLOP is mathematically formulated in this study. In this formulated problem, the objective function is to achieve the minimum value of the square errors between the experimentally measured PEMFC voltage and the determined voltages by the developed model. The CGO algorithm is implemented explicitly to minimize the FF. The theoretical model's simulation effects are also tested at different temperatures and pressures.

The contribution of this research study can be summarized as: (1) the static theoretical models of the different types of PEMFCs are introduced and the estimated output voltages of the PEMFCs are compared with the measured voltages to evaluate the adequateness of the model, and (2) the robustness of the proposed CGO algorithm in minimizing the objective function is verified by comparing the results with other optimization methods. 


\section{Modeling of The PEMFCS Methods}

To explain PEMFC equations and to assess their simulation effectiveness, the model given by Mann et al. [22] is chosen. This model is often used as a reference for the research analysis in more than one literature paper. The number of series cells $\left(N_{\text {cells }}\right)$ is expressed by (1) [22-24] in the mathematical equation of terminal voltage from the PEM fuel cell $\left(V_{\text {stack }}\right)$.

$$
V_{\text {stack }}=N_{\text {cells }} \cdot\left(E_{\text {nernst }}-v_{\text {act }}-v_{\Omega}-v_{\text {conc }}\right)
$$

where $E_{n e r n s t}$ is the Nernst voltage of a cell, $v_{\text {act }}$ is the overpotential of cell activation, $v_{\Omega}$ is the ohmic voltage drop in the cell, and $v_{c o n c}$ is the over-potential of the concentration. If the temperature is below $100{ }^{\circ} \mathrm{C}, E_{\text {nernst }}$ is calculated using Equation (2). The voltage drops $v_{a c t}, v_{\Omega}$, and $v_{\text {conc }}$ can be calculated using (3)-(5), respectively [22,24].

$$
\begin{gathered}
E_{\text {Nernst }}=1.229-0.85 \times 10^{-3}\left(T_{f c}-298.15\right)+4.3085 \times 10^{-5} T_{f c} \ln \left(P_{\mathrm{H}_{2}} \sqrt{P_{\mathrm{O}_{2}}}\right) \\
v_{a c t}=-\left[\xi_{1}+\xi_{2} T_{f c}+\xi_{3} T_{f c} \ln \left(C_{\mathrm{O}_{2}}\right)+\xi_{4} T_{f c} \ln \left(I_{f_{c}}\right)\right] \\
E_{\text {Nernst }}=1.229-0.85 \times 10^{-3}\left(T_{f c}-298.15\right)+4.3085 \times 10^{-5} T_{f c} \ln \left(P_{\mathrm{H}_{2}} \sqrt{P_{\mathrm{O}_{2}}}\right) \\
E_{\text {Nernst }}=1.229-0.85 \times 10^{-3}\left(T_{f c}-298.15\right)+4.3085 \times 10^{-5} T_{f c} \ln \left(P_{\mathrm{H}_{2}} \sqrt{P_{\mathrm{O}_{2}}}\right) \\
v_{\text {act }}=-\left[\xi_{1}+\xi_{2} T_{f_{c}}+\xi_{3} T_{f c} \ln \left(C_{\mathrm{O}_{2}}\right)+\xi_{4} T_{f c} \ln \left(I_{f c}\right)\right]
\end{gathered}
$$

where

$$
\begin{aligned}
& C_{\mathrm{O}_{2}}=\frac{P_{\mathrm{O}_{2}}}{5.08 .10^{6}} \cdot \exp \left(498 / T_{f c}\right) \\
& v_{\Omega}=I_{f c}\left(R_{m}+R_{c}\right) ; R_{m}=\frac{\rho_{m} l}{M_{A}}
\end{aligned}
$$

where

$$
\begin{gathered}
\rho_{m}=\frac{181.6\left[1+0.03\left(\frac{I_{f c}}{M_{A}}\right)+0.062\left(\frac{I_{f c}}{303}\right)^{2}\left(\frac{I_{f c}}{M_{A}}\right)^{2.5}\right]}{\left[\lambda-0.634-3\left(\frac{I_{f c}}{M_{A}}\right)\right] \cdot \exp \left[4.18\left(\frac{T_{f c}-303}{T_{f c}}\right)\right]} \\
v_{\text {conc }}=-\beta \cdot \ln \left(1-\frac{J}{J_{\max }}\right)
\end{gathered}
$$

where $T_{f c}$ represents the PEMFC temperature in Kelvin $(\mathrm{K}), P_{H}$ and $P_{O}$ are the hydrogen $\left(\mathrm{H}_{2}\right)$ pressure and oxygen $\left(\mathrm{O}_{2}\right)$ pressure, respectively, $\mathrm{I}_{\mathrm{fc}}$ is the fuel cell current $(\mathrm{A}), M_{A}$ is the membrane surface area $\left(\mathrm{cm}^{2}\right), \mathrm{C}_{\mathrm{O}_{2}}$ is the concentration of $\mathrm{O}_{2}\left(\mathrm{~mol} / \mathrm{cm}^{3}\right), \xi_{1}-\xi_{4}$ are semi-empirical factors, $R_{m}$ denotes the membrane resistance $(\Omega), R_{c}$ is the leads' resistances $(\Omega), 1$ is the membrane thickness $(\mathrm{cm}), \rho_{m}$ denotes the membrane resistivity $(\Omega . \mathrm{cm}), \lambda$ is a tunable design variable, $\beta$ represents a constant of an empirical range, $J$ refers to the current density $\left(\mathrm{A} / \mathrm{cm}^{2}\right)$, and $J_{\max }$ is the maximum current density $\left(\mathrm{A} / \mathrm{cm}^{2}\right)$.

$\xi_{1}-\xi_{4}$ are design variables which are established according to the geometrical dimensioning and the material resources of the manufactured fuel cells [23]. The fact that the design variable $\lambda$ is dependent on different factors such as relative humidity, the stoichiometric ratio, makes its design a complex task. Hence, in this paper, the value of $\lambda$ is assumed to be varied from 13 to 23 . As $\lambda$ becomes less, this indicates higher cell relative humidity. On the other hand, as $\lambda$ becomes greater, it is an indication of the supersaturated conditions $[7,22,23] . \beta$ is a design variable for Equation (5) which can be computed using Equation (6).

$$
\beta=\frac{\Re \cdot T_{f c}}{2 \alpha F}
$$

where $\Re$ is the ideal gas constant, $F$ refers to the Faraday's constant, and $\alpha$ is the charge transfer coefficient. 
It can be noted from Equations (5) and (6) that the drop in the concentration voltage follows a linear relationship with the temperature and the current density.

There are seven design variables (i.e., $\xi_{1}-\xi_{4}, \lambda$, Rc, and $\beta$ ) to be determined when constructing the model for the PEM fuel cells to utilize it in any further electric power system investigations.

\section{Problem Formulation}

The problem introduced in this article is solved using the newly developed CGO algorithm. The PEMFC model introduces nonlinear characteristics including multiple unknown design variables due to a shortage in manufacturing data about PEMFCs. Therefore, a detailed model is a challenge that must be addressed. To achieve the unique, dependable model, there are seven design variables to be tuned. These variables must be accurately calculated in order to minimize the FF. The FF is the sum of the square of the errors which is the difference between the terminal voltage calculated from the PEMFC and the terminal voltage observed by measurements as provided in Equation (7) [21,23]. The proposed fitness function is minimized by using the CGO algorithm. The solution of the optimization problem yields the design value for the aforementioned design variables: $\xi_{1}-\xi_{4}, \lambda, \mathrm{Rc}$, and $\beta$ [25].

$$
F F=(S S E)=\left(\sum_{m=1}^{N_{\text {samples }}}\left[V_{F C, \exp }(m)-V_{F C, \text { est }}(m)\right]^{2}\right)
$$

where $N_{\text {samples }}$ refers to the number of the voltages measured, $m$ defines the iteration number, $V_{F C, \exp }$ is the PEMFC measured voltage (V), and $V_{F C, e s t}$ is the PEMFC computed voltage by the introduced model $(\mathrm{V})$.

\section{The Chaos Game Optimization Algorithm}

Studying the use of chaotic systems attracted many researchers as the theme of chaos achieves a high interdisciplinary level [26]. Employing the chaotic systems in the optimization algorithms is an example, a new metaheuristic Chaos Game Optimization is introduced. The CGO algorithm's key concept is based on the chaos theory in which fractals are configured through the technique of the chaos game. The theory of chaos game is used as the key principle of the algorithm in the CGO method.

\subsection{Inspiration}

Chaos theory focuses on the basic characteristics of dynamically sensitive systems to the initial conditions. In view of the randomness of these complex processes, the principle of chaos refers to the presence of certain fundamental patterns.

The method of constructing fractals using the initial form and a random initial point is the Chaos Game. The main goal is to construct an iterative sequence of points to enter a sketch of similar form in various scales. Firstly, it is important to correctly place a triangle vertex. A random, initial point for the formation of fractal is chosen. The next item is then calculated as a part of the space between the first point and the random vertex. A fractal is generated while repeating this step with regard to the initial point and the vertex selected. Initially, the principal fractal form, which is triangular, is formed by three vertices. Dice with two, red, blue and green faces are used. The fractal, which is a seed, is chosen as a first random point. The first seed is pushed towards the corresponding vertex in the middle of the gap between the seed and the vertex while the dice are rolled, according to which color is selected. In the next iteration, the new location of the seed is used. The Sierpinski triangle is obtained by rolling the dice several times. The schematic explanation of such an approach is shown in Figure 1. 


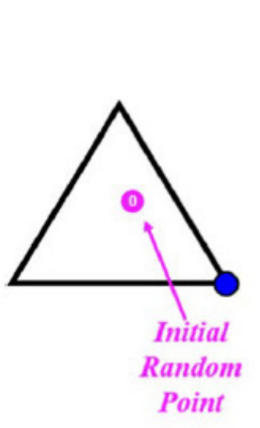

Step 1

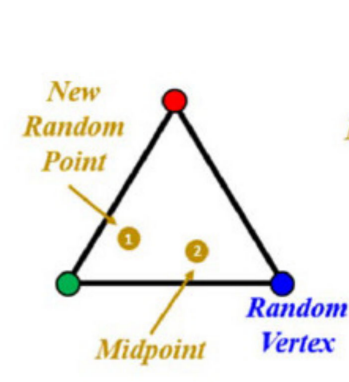

Step 2

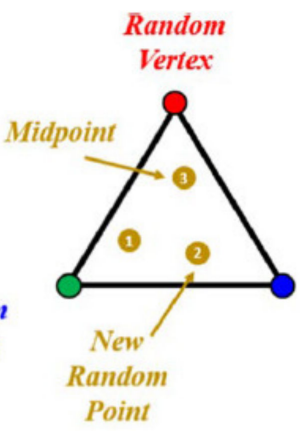

Step 3

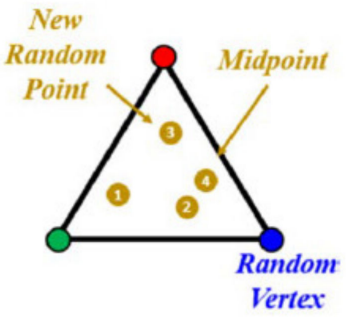

Step 4 ...

Figure 1. The approach of chaos game to create the Sierpinski triangle.

\subsection{Mathematical Model}

A number of solution candidates $(X)$ representing the seeds is assumed by the CGO algorithm. Each candidate solution $\left(X_{i}\right)$ consists of some tuneable variables $\left(X_{i, j}\right)$ representing the seed's location. The triangle of Sierpinski is considered the exploration field looking for solutions. The following is the mathematical representation:

$$
X=\left[\begin{array}{c}
X_{1} \\
X_{2} \\
\vdots \\
X_{i} \\
\vdots \\
X_{n}
\end{array}\right]=\left[\begin{array}{cccccc}
x_{1}^{1} & x_{1}^{2} & \cdots & x_{1}^{j} & \cdots & x_{1}^{d} \\
x_{2}^{1} & x_{2}^{2} & \cdots & x_{2}^{j} & \cdots & x_{2}^{d} \\
\vdots & \vdots & \vdots & \vdots & \ddots & \vdots \\
x_{i}^{1} & x_{i}^{2} & \cdots & x_{i}^{j} & \cdots & x_{2}^{d} \\
\vdots & \vdots & \vdots & \vdots & \ddots & \vdots \\
x_{n}^{1} & x_{n}^{2} & \cdots & x_{n}^{j} & \cdots & x_{n}^{d}
\end{array}\right],\left\{\begin{array}{l}
i=1,2, \ldots, n . \\
i=1,2, \ldots, d .
\end{array}\right.
$$

where $n$ represents the population size of the exploration field while $d$ refers to the problem dimension. The initialization of the seeds is random as follows:

$$
x_{i}^{j}(0)=x_{i, \text { min }}^{j}+\text { rand. }\left(x_{i, \text { max }}^{j}-x_{i, \text { min }}^{j}\right),\left\{\begin{array}{l}
i=1,2, \ldots, n . \\
i=1,2, \ldots, d .
\end{array}\right.
$$

where $x_{i}^{j}(0)$ is the initial population, $x_{i, \min }^{j}$ and $x_{i, \max }^{j}$ refer to the min. and max. values for the $j$ th design variable, and rand is a random number between 0 and 1.

To finalize the structure of a triangle, the mathematical model generates different seeds within their upper and lower limits. A temporary triangle with three seeds is drawn as follows:

- The Global Best (GB) found so far;

- The Mean Group (MGi) which is the mean values of random seeds;

- $\quad$ The $i$ th solution candidate $\left(X_{i}\right)$.

The vertices of the triangle are GB, MGi and $X_{i}$. A temporary triangle is generated for each initial seed to generate new seeds to complete a new triangle. The basic schemes of the formation of temporary triangles are shown in Figure 2.

The $i$ th iteration contains the three corners of a Sierpinski triangle and the seeds obtained in the previous iteration. For new seeds, the temporary triangle is used. The dice are rolled. The seed in $X_{i}$ is transferred to the GB or to the MGi depending on the resulting color. This is modeled by a random integer function. It generates two integers, either 0 or 1 , to allow green or red faces to be selected. According to the chaos game, seed movement should be minimal. 

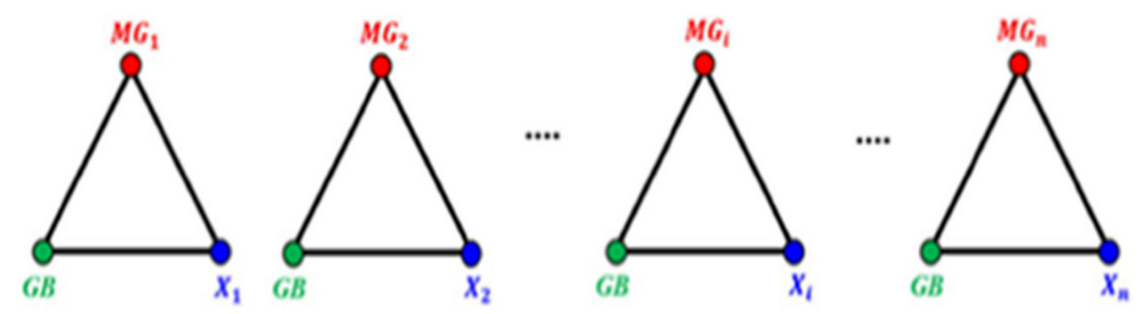

(a)

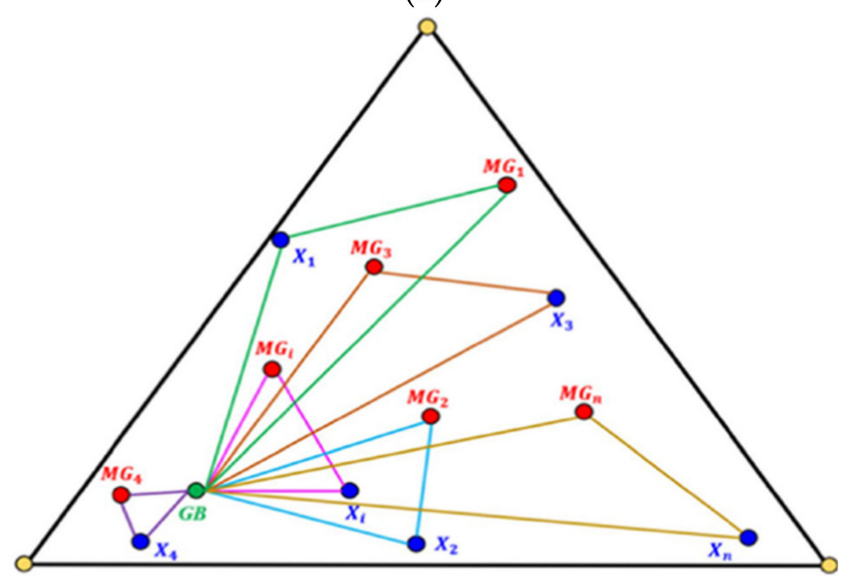

(b)

Figure 2. (a) Formation of sub-triangles; (b) sub-triangles inside the exploration field.

Some generated factorials are used in this regard. The defined process for the first seed is presented mathematically as follows:

$$
\operatorname{Seed}_{i}^{1}=X_{i}+\alpha_{i} \times\left(\beta_{i} \times G B-\gamma_{i} \times M G_{i}\right), i=1,2, \ldots, n
$$

where $X_{i}$ refers to the $i$ th candidate, $\alpha_{i}$ defines the random factorial which limits the seeds' movement, and $\beta_{i}$ and $\gamma_{i}$ are random integers of 0 or 1 representing the probability of rolling some dice.

Dice of three blue and red faces are used for the second seed (GB). The dice are rolled, and the GB is shifted to $X_{i}$ or MGi, according to the resulting color. The seed moves towards the $X_{i}$ when a blue face is raised; if the red face is raised, the seed moves towards the MGi. The second seed goes towards a point on the connecting lines between $X_{i}$ and MGi. The following equation describes this mathematically:

$$
\operatorname{Seed}_{i}^{2}=G B+\alpha_{i} \times\left(\beta_{i} \times X_{i}-\gamma_{i} \times M G_{i}\right), i=1,2, \ldots, n
$$

Regarding the third seed, the dice are rolled. According to the resulting color, the seed moves towards the $X_{i}$ or GB, which produces only two integrals as 0 and 1 . According to some random factors, the seed will travel towards the connected lines between the $X_{i}$ and GB as expressed in Equation (12).

$$
\operatorname{Seed}_{i}^{3}=M G_{i}+\alpha_{i} \times\left(\beta_{i} \times X_{i}-\gamma_{i} \times G B\right), i=1,2, \ldots, n
$$

Another method is also used to create the fourth seed to introduce a mutation step in the location updates of the seeds. The location modification is based on certain changes in the selected decisions. The mathematical model of the process mentioned is:

$$
\operatorname{Seed}_{i}^{4}=X_{i}\left(x_{i}^{k}=x_{i}^{k}+R\right), k=[1,2, \ldots, d] .
$$

where $k$ represents a random integer between 1 and $d$, and $R$ represents random number ranges from 0 to 1 . 
Four different formulations for $\alpha_{i}$ which regulate the motion limitations of the grain are presented to monitor and change the exploration and exploitation rate of the CGO algorithm as follows:

$$
\alpha_{i}=\left(x_{i}^{k}=x_{i}^{k}+R\right)\left\{\begin{array}{c}
\text { Rand } \\
2 \times \text { Rand } \\
(\delta \times \text { Rand })+1 \\
(\varepsilon \times \text { Rand })+(\sim \varepsilon)
\end{array}\right.
$$

where Rand denotes random number ranges from 0 to 1 , and $\delta$ and $\varepsilon$ refer to random factors between 0 and 1 .

The fitness of new candidates is compared with the present ones and those of high fitness are kept, meanwhile, the candidates with lower fitness are rejected.

The pseudo-code of the CGO is expressed as follows:

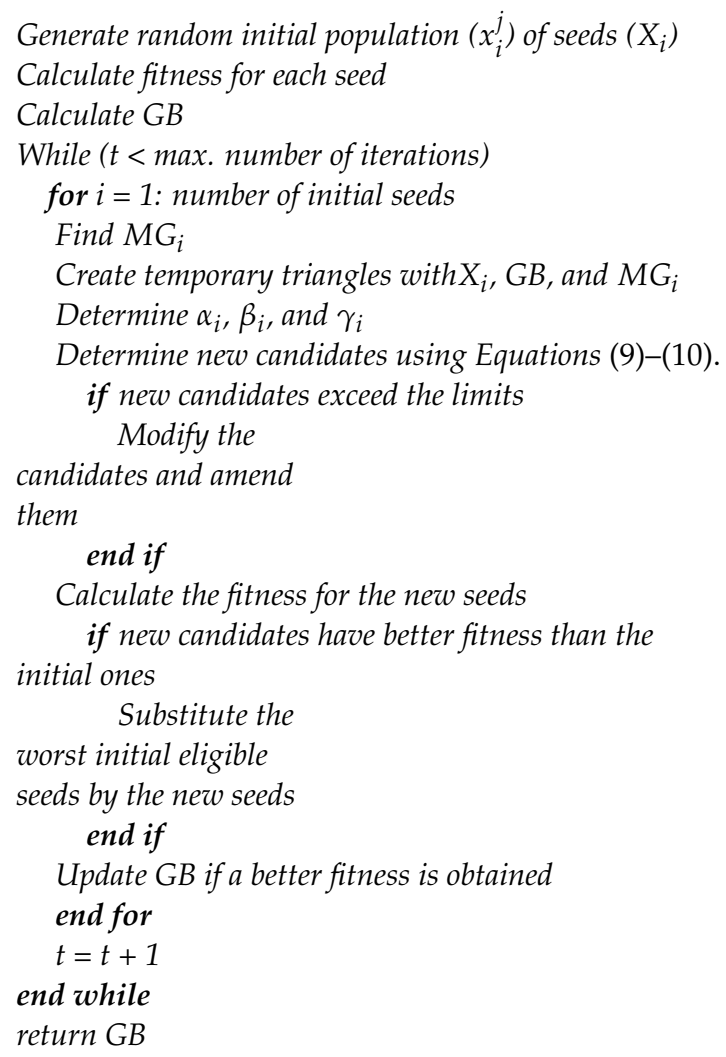

\section{Simulation Results}

Three test cases of PEMFCs are investigated in this work. The considered PEMFCs are Ballard Mark V, AVISTA SR-12 $500 \mathrm{~W}$, and the $6 \mathrm{~kW}$ Nedstack PS6 PEMFCs. Experimental measurements are observed for the currents, voltages, and their characteristics. These data are used in the assessment of the efficacy of newly developed CGO by calculating the unknown seven PEM fuel cell design variables. The details of the upper and lower limits of the design variables for the PEMFCs are found in [23,27-29]. Since the design variables can be calculated offline, the time needed for simulation is not the highest priority. However, the simulation time of the proposed CGO is also contrasted with the times of other approaches. These simulations are tested on a Microsoft Windows 10 Pro 64-bit version: 'R2014b' MATLAB platform (10.0, Build 18363). The MATLAB $\mathrm{m}$-files are run on a Toshiba 2.00 GHz AMD A8-6410 CPU, fitted with 4 GB of RAM. In the following sections, the results of more detailed simulation are shown with respect to the SSE convergence and the I/V polarization curves for the three studied cases of PEMFCs. 


\subsection{Case One: The Ballard Mark V}

The characteristics of the PEMFC used in this case are illustrated in Table 1. The first case fuel cell used in this experiment contains 35 cells connected in series. The current flowing through the fuel cell under test should not exceed 70 A due to thermal considerations.

Table 1. Characteristics of PEMFC of case one.

\begin{tabular}{cc}
\hline Item & Value \\
\hline No. of series cells & 35 \\
Membrane thickness & $178 \mu \mathrm{m}$ \\
Surface area $\left(M_{A}\right)$ & $50.6 \mathrm{~cm}^{2}$ \\
Thermal limit of the current & $70 \mathrm{~A}$ \\
Maximum current density & $1.5 \mathrm{~A} / \mathrm{cm}^{2}$ \\
\hline
\end{tabular}

Figure 3 depicts the convergence behavior of the objective function during 2000 iterations. The convergence curve represents how the objective function-which is the sum of the squared errors-decreases through the iterations. It can be noted that the proposed CGO algorithm converges fast and smooth. It requires less than 200 iterations to reach a solution close to the final solution at the end of 2000 iterations. For further analysis of the simulation findings of the newly developed optimization method, the I/V curves are provided in Figure 4. It shows a comparison between the estimated voltage by the model and 13 samples of voltages observed experimentally. The blue curve, which is the calculated voltage by the proposed PEMFC model, best fits the 13 voltage readings, which are shown as red crosses, measured experimentally in the lab. The current vs voltage curves show that as the voltage of the fuel cell decreases upon the increase in the drawn current, the appropriate fitting between the estimated and observed voltages is clear. Additionally, the I/P relationship is shown in Figure 5. The blue curve, which is the calculated output power by the proposed PEMFC model, best fits the 13 power readings, which are shown as red crosses, calculated from the measured voltages and currents. As the current increases, more power can be provided by the fuel cell. It validates the exactness of the model and its capability to estimate very close results to those observed in the laboratory.

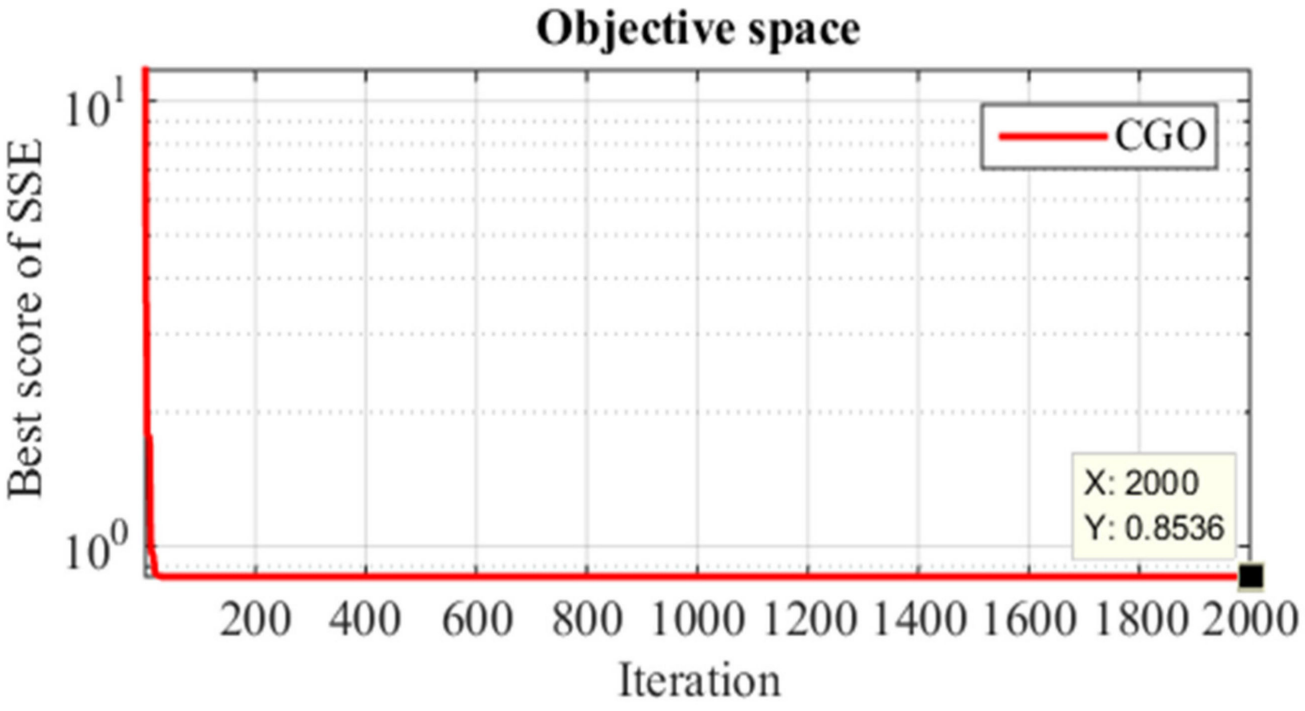

Figure 3. Convergence curve of the CGO method in the case of Ballard Mark V. 


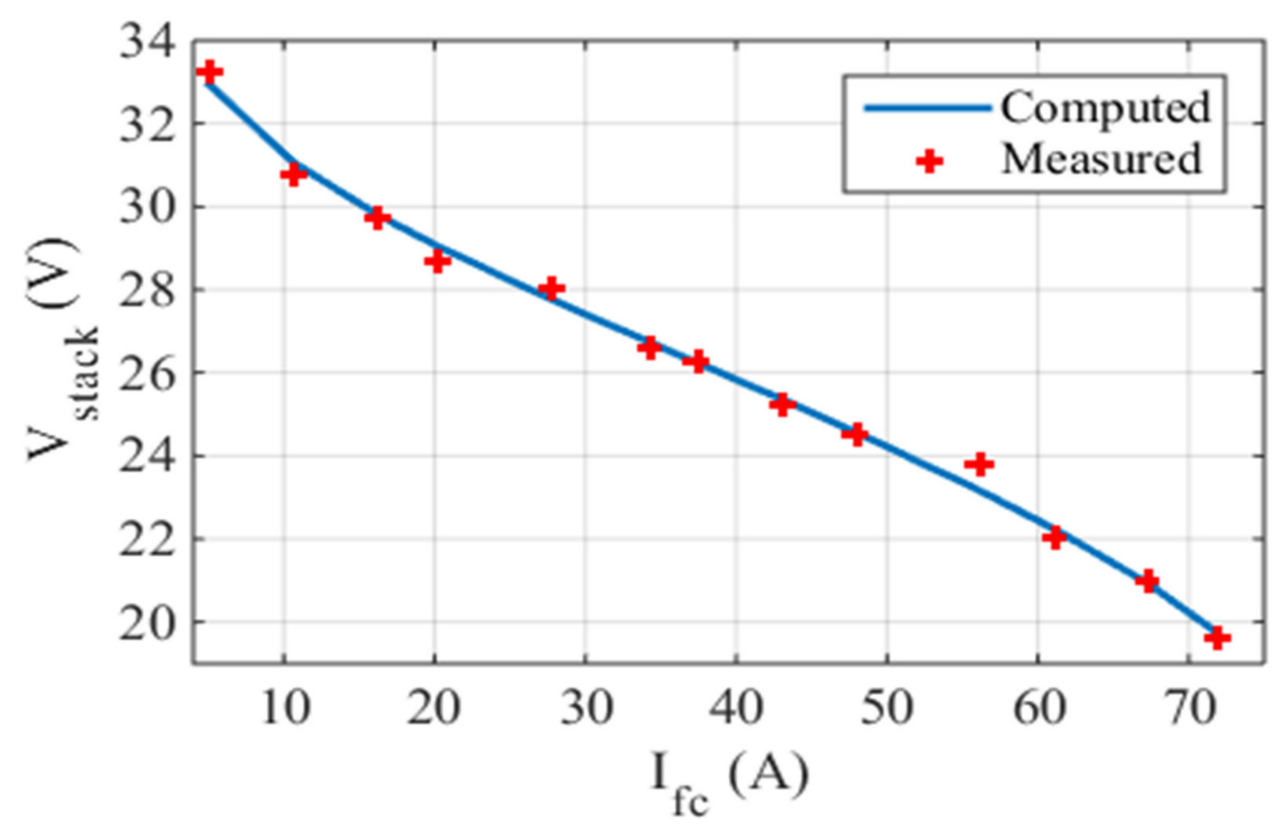

Figure 4. Comparison between estimated and practical current-voltage relationship of Ballard Mark V.

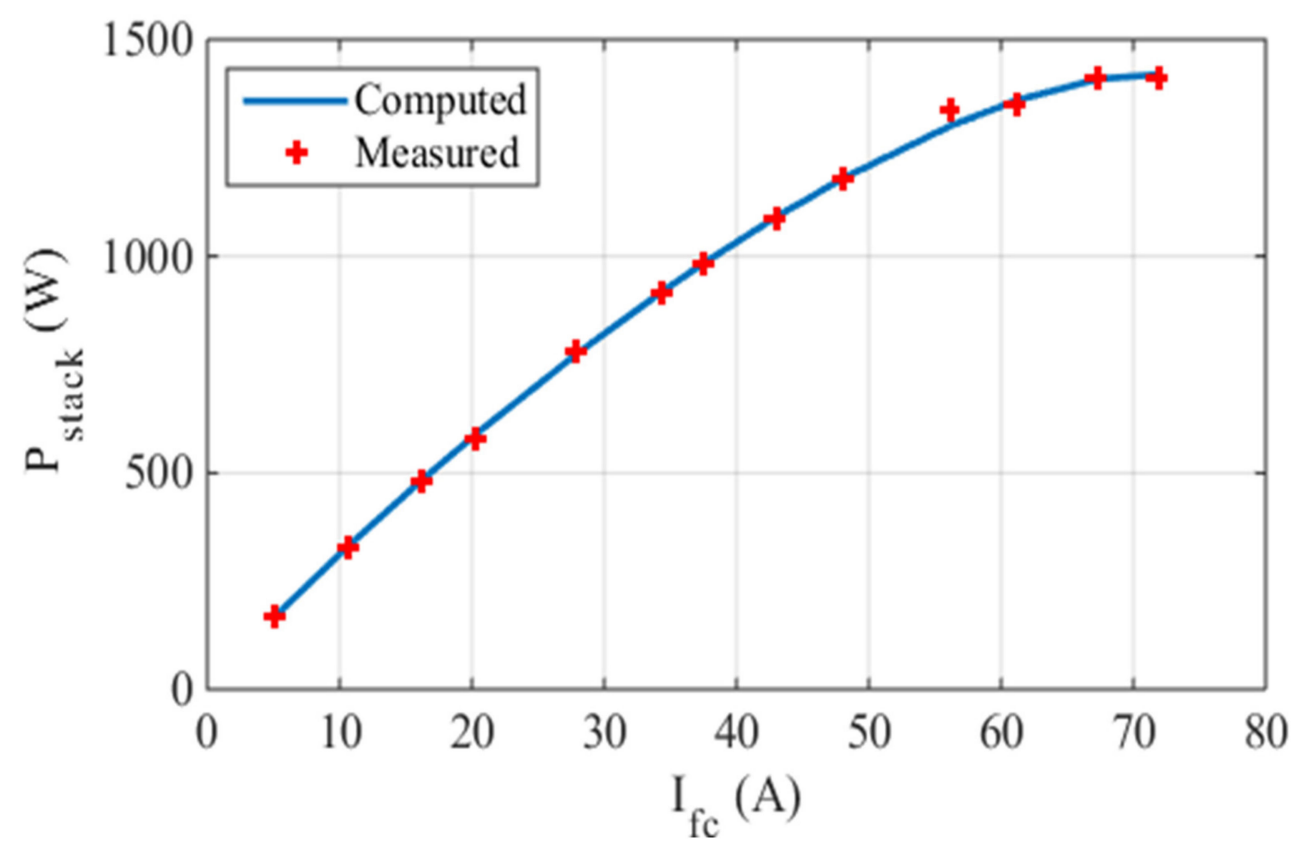

Figure 5. Comparison between estimated and practical current-power relationship of Ballard Mark V.

Further comparisons between the newly developed CGO method versus other optimization methods, used in the literature, are shown in Table 2. It presents the best candidate solutions of the seven design variables $\left(\xi_{1}-\xi_{4}, \lambda, R_{c}\right.$, and $\left.\beta\right)$ obtained by each optimization method. This table also shows the settings of the optimization which are: the population size, the number of iterations, and the time taken by each optimization method in seconds to finish the simulation. Finally, the best result of the objective function achieved by each optimization method is shown in the last row. 
Table 2. Decision variables for the optimization problem of case one.

\begin{tabular}{ccccc}
\hline Parameter & CGO & HOA & WOA [29] & GHO [23] \\
\hline$\xi_{1}(V)$ & -1.192042466678 & -0.8532 & -1.1978 & -0.8532 \\
$\xi_{2} \times 10^{-3}(V / K)$ & 3.6124342507723 & 3.3244899099 & 4.4183 & 3.4173 \\
$\xi_{3} \times 10^{-5}(V / K)$ & 4.0797209285374 & 9.1704275491 & 9.7214 & 9.8 \\
$\xi_{4} \times 10^{-5}(V / K)$ & -16.283043067932 & -15.445073095 & -16.273 & -15.9555 \\
$\lambda$ & 23 & 22.999998286 & 23 & 22.8458 \\
$R_{c}(\mathrm{~m} \Omega)$ & 0.1 & 0.249053165 & 0.1002 & 0.1 \\
$\beta$ & 0.0136000000000001 & 0.0136 & 0.0136 & 0.0136 \\
Population size & 50 & 20 & 50 & 60 \\
Number of iterations & 2000 & 2000 & 2000 & 2000 \\
Computation time $(\mathrm{s})$ & 119.38140 & 11.4236416 & 111 & 95.5 \\
$S S E$ & 0.8536075155595 & 0.9424006399 & 0.8537 & 0.871 \\
\hline
\end{tabular}

There are internal losses (voltage drop) in the voltage of the PEMFC such as $\mathrm{V}_{\text {ohmic }}$, $\mathrm{V}_{\text {act }}$, and $\mathrm{V}_{\text {conc }}$. The ohmic losses $\left(\mathrm{V}_{\text {ohmic }}\right)$ increases linearly upon the current increase. $\mathrm{V}_{\text {act }}$ has the highest effect on the total voltage drop (losses). Meanwhile, $\mathrm{V}_{\text {conc }}$ has the lowest effect on the total $V_{\text {losses. }}$. The plot of the relation between the internal voltage losses and the current is shown in Figure 6. The simulations are done more than once under different temperatures $\left(30^{\circ} \mathrm{C}, 50{ }^{\circ} \mathrm{C}\right.$, and $\left.70{ }^{\circ} \mathrm{C}\right)$ at constant partial pressures $\left(\mathrm{P}_{\mathrm{H}_{2}} / \mathrm{P}_{\mathrm{O}_{2}}=1 / 1 \mathrm{~atm}\right)$ to investigate the effect of tuning the temperature on the voltage. This investigation and results are shown in Figure 7. It is noted that the PEMFC output voltage increases when the temperature rises at the same pressure. The difference between the output voltage values at different temperatures increases slightly at higher values of current. In Figure 8, the output power of the fuel cell is plotted against the current. It is observed that the effect of changing the temperature on the output power increases more at higher values of current. Meanwhile, at lower values of current the effect of temperature can hardly be observed.

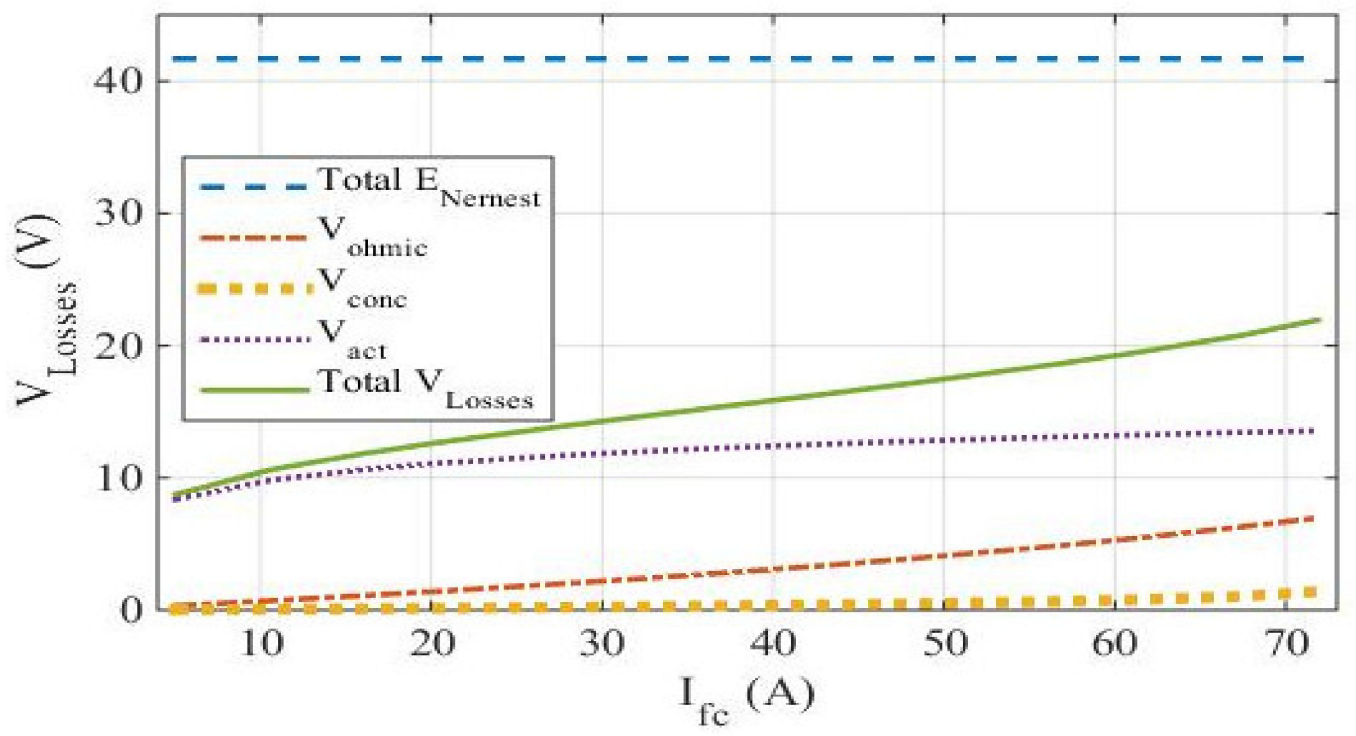

Figure 6. Internal voltage losses in case of Ballard Mark V.

Besides studying the impact of temperature, the simulations are also done under the different pressures at constant temperature to measure the effect of tuning the pressure on the PEMFC voltage. The resulted I/V curves are shown in Figure 9 which show that the voltage increases when the pressure increases. In Figure 10, the output power of the fuel cell is plotted against the current. It is observed that the effect of changing the pressure on the output power increases at higher values of current. However, when comparing the effect of changing the temperature at constant pressure and vice versa, it is observed that 
the effect of the temperature on the output power is much higher. Therefore, changing the temperature leads to a wide range of output power from the fuel cell.

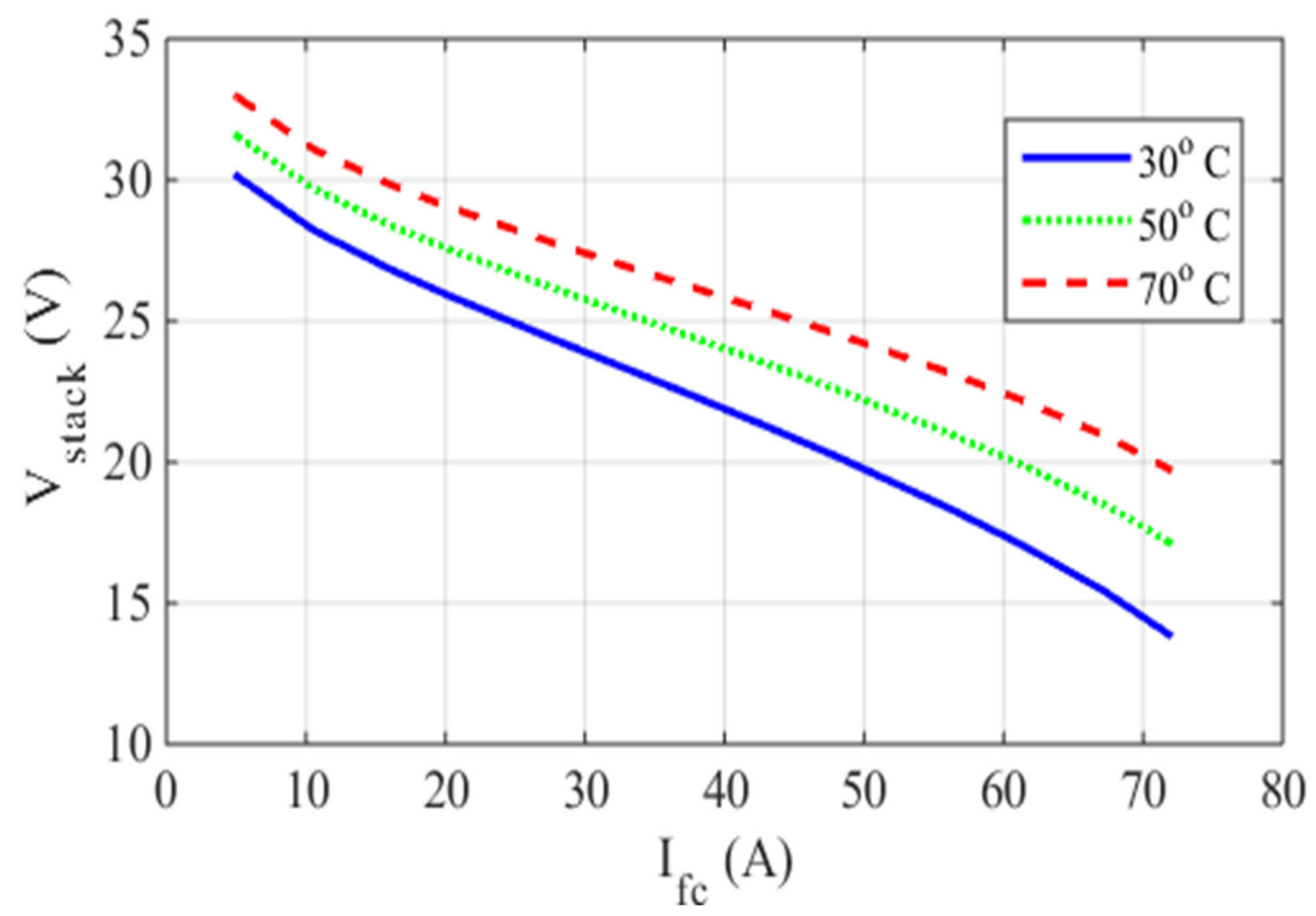

Figure 7. Comparison between I/V curves under various temperatures in case of Ballard Mark V PEMFC.

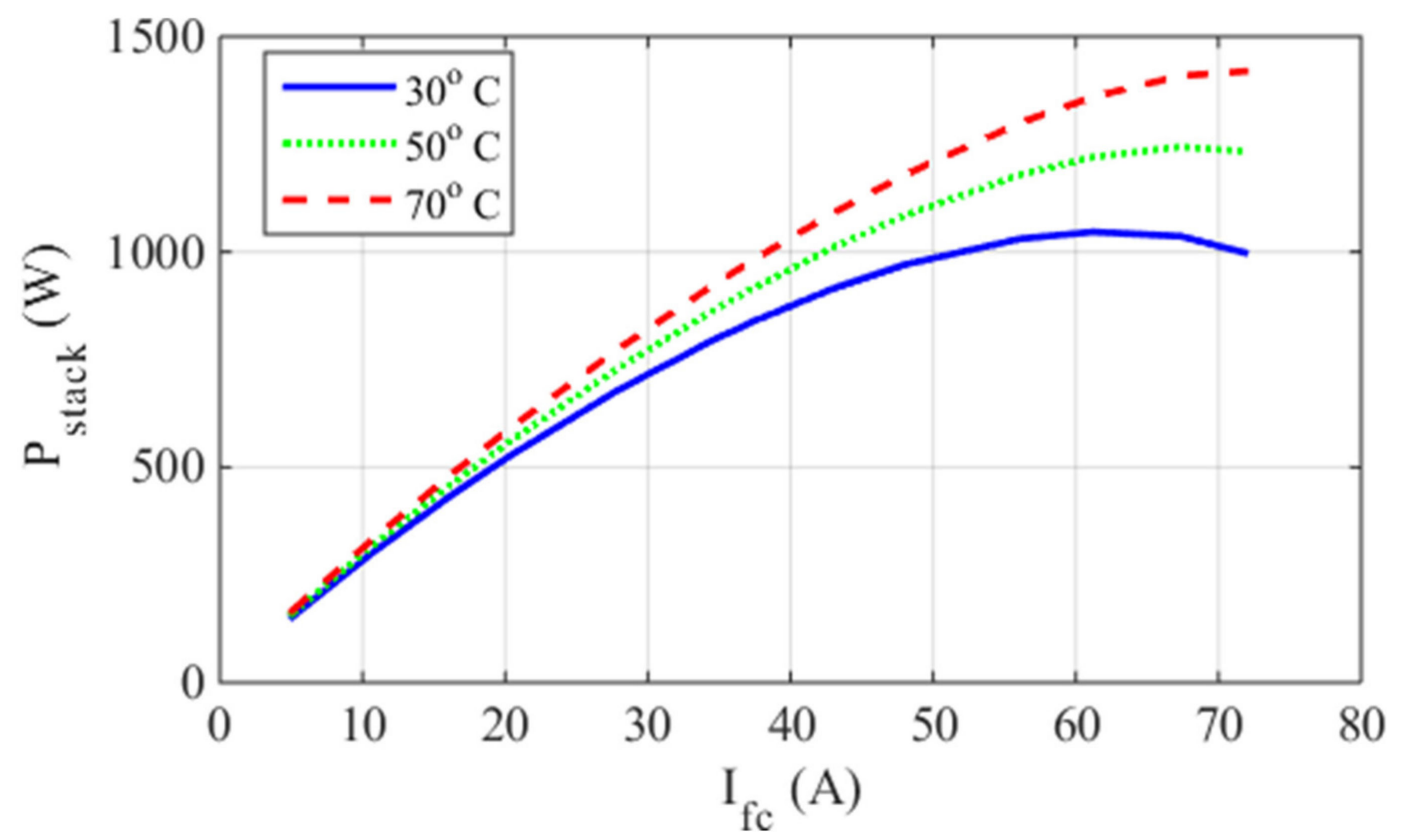

Figure 8. Comparison between I/P curves under various temperatures in case of Ballard Mark V PEMFC. 


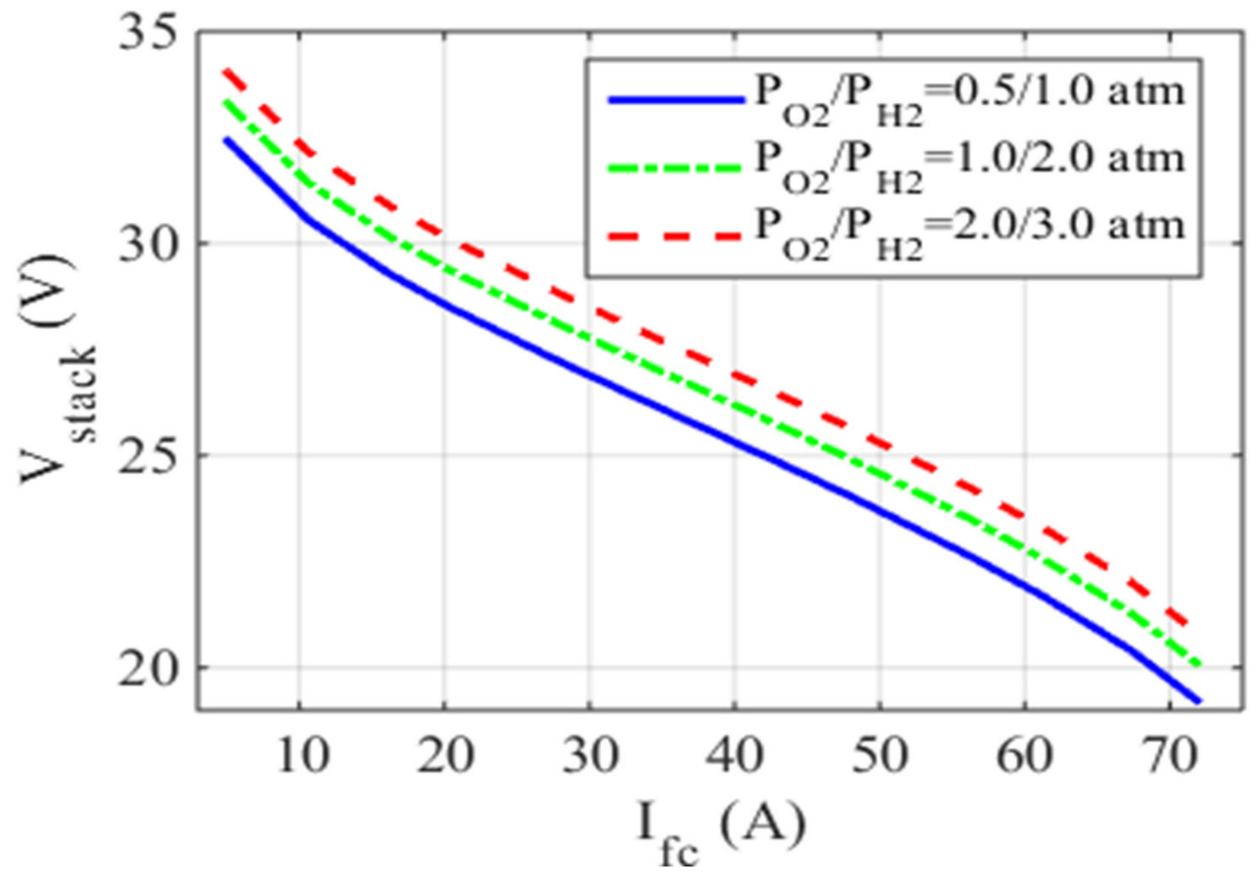

Figure 9. Comparison between I/V curves under various pressures in case of Ballard Mark V PEMFC.

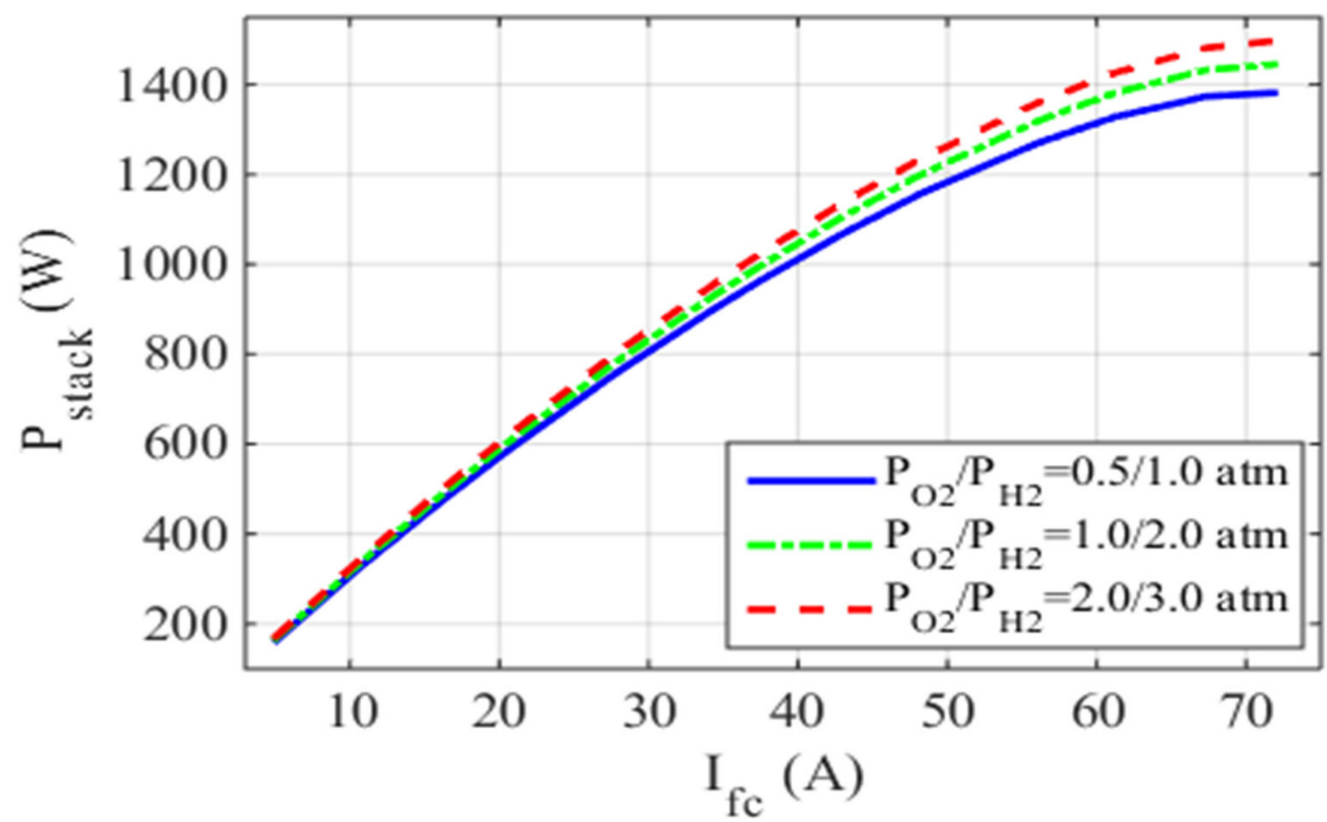

Figure 10. Comparison between I/P curves under various pressures in case of Ballard Mark V PEMFC.

\subsection{Case Two: The AVISTA SR-12 $500 \mathrm{~W}$}

The test in the second case of this research study is conducted on 48 cells connected in series, AVISTA SR-12 $500 \mathrm{~W}$ PEMFC. The specifications of the AVISTA SR-12 500 W PEM fuel cell are found in [25,28,30-32]. Figure 11 shows the convergence curve of the objective function for 2000 iterations. 


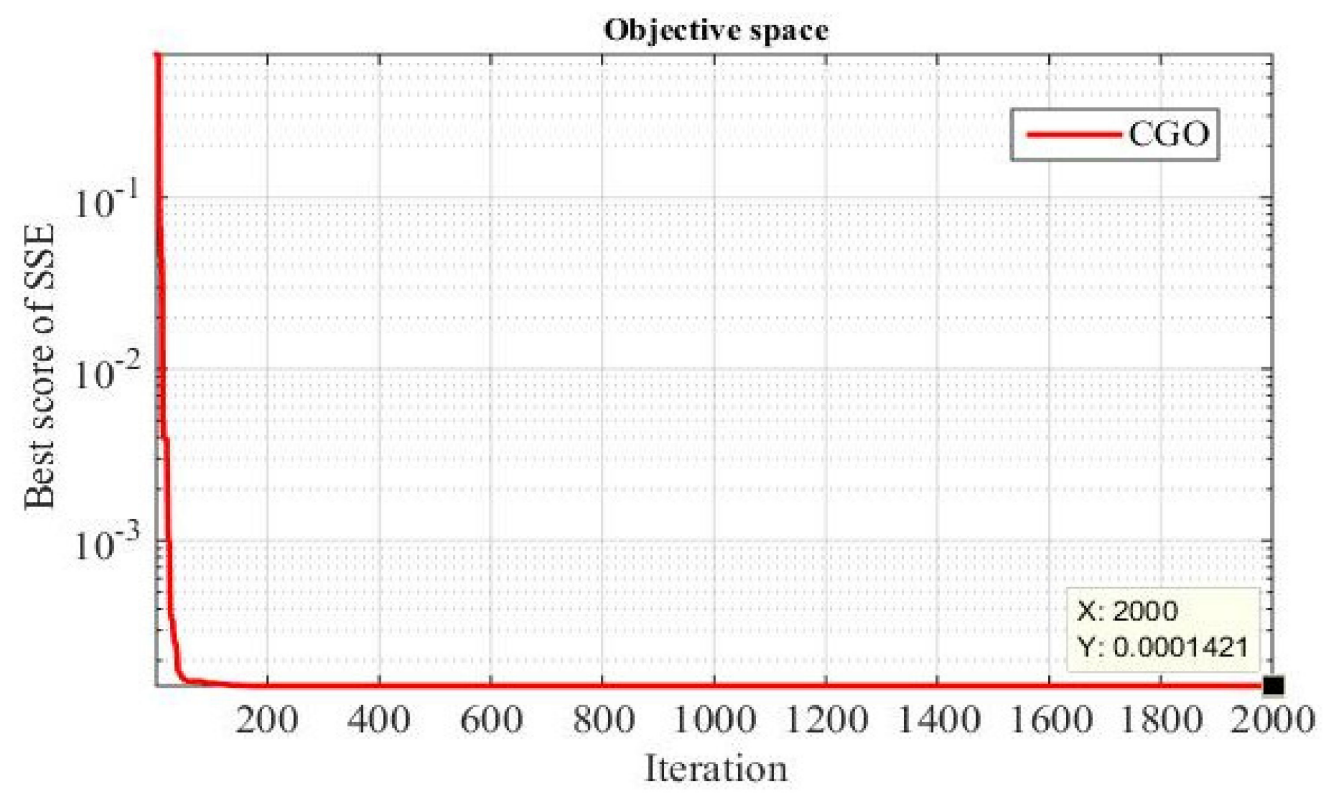

Figure 11. Convergence curve of the CGO method in case of AVISTA SR-12 $500 \mathrm{~W}$.

Moreover, Figure 12 presents the I-V characteristics in which the voltage measured for 20 samples is compared with the voltage of the developed model. It can be clearly observed that both voltages are close in value. Regarding the fuel cell of case two, the blue curve of the calculated voltages follows the measured voltage-red marks-much better than that in the case one fuel cell. The relationship between the fuel cell current and power are provided in Figure 13. The results shown in these figures assure the robustness of the model. The values of the measured powers, marked in red, almost satisfy the blue curve of the estimated output power of the fuel cell.

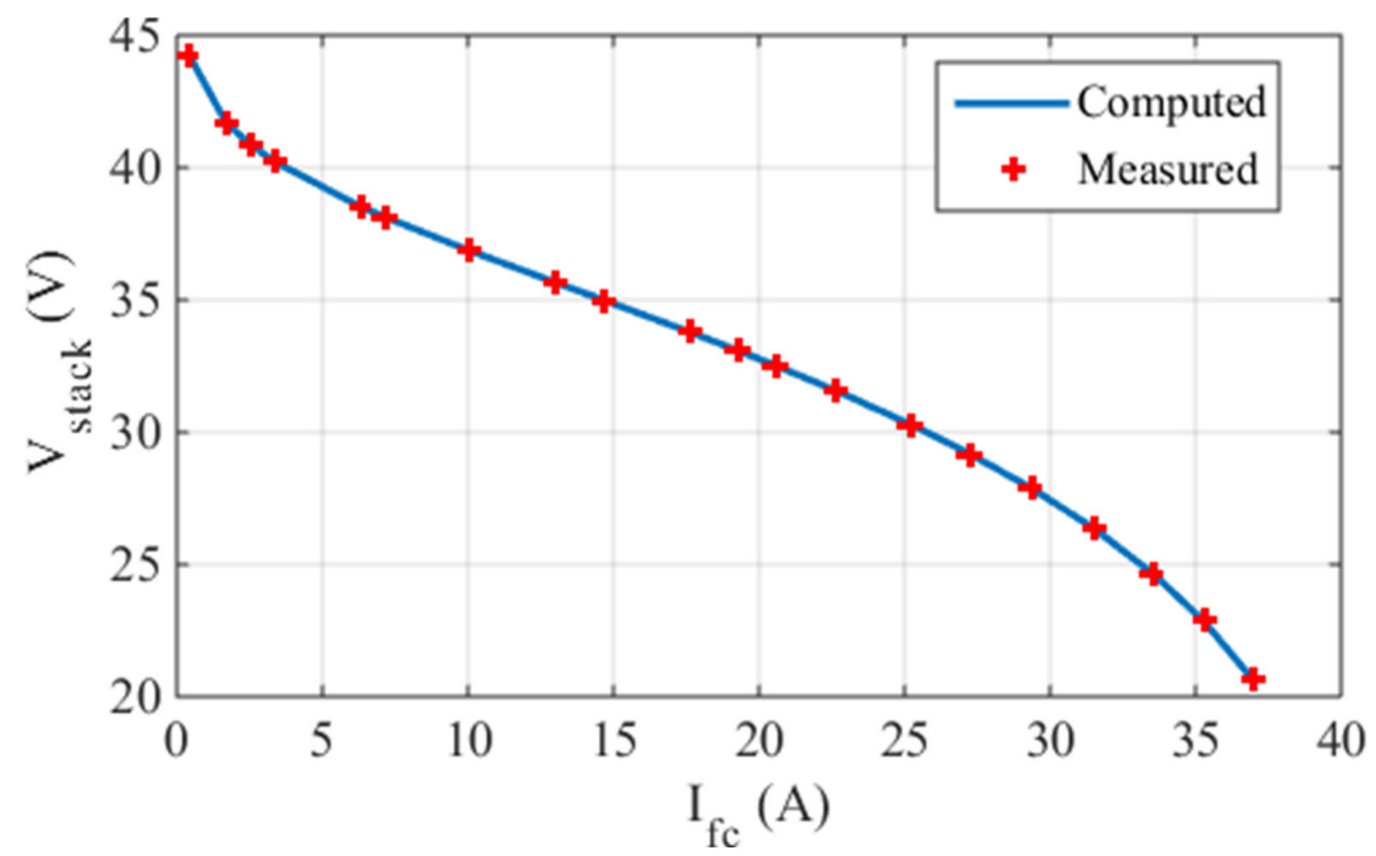

Figure 12. Comparison between estimated and practical current-voltage relationship of AVISTA SR-12 $500 \mathrm{~W}$. 


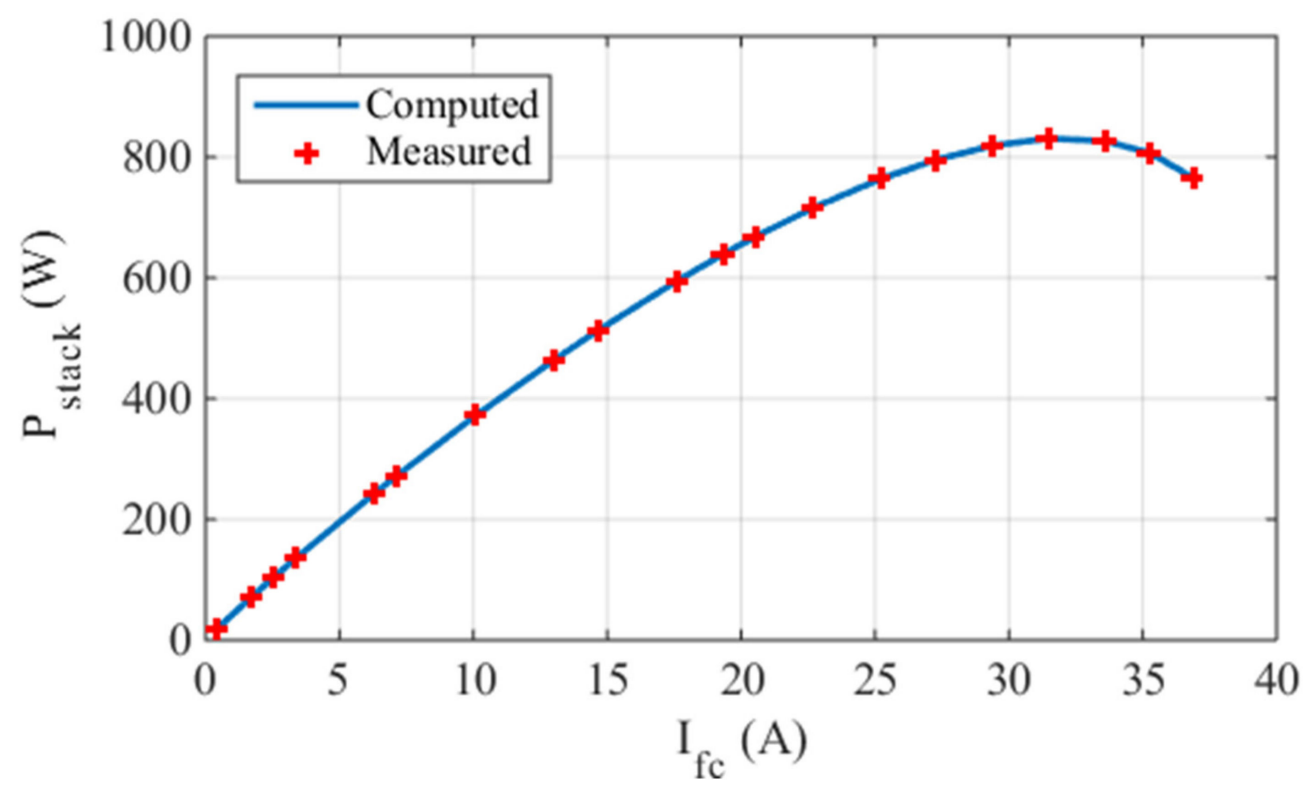

Figure 13. Comparison between estimated and practical current-power relationship of AVISTA SR-12 500 W.

Further numerical comparisons between the newly developed CGO method and other methods in extracting the design variables of the same PEMFC type of case two is given in Table 3. It provides the values of the seven design variables, the best solution, and the simulation time taken by each optimization method.

Table 3. Decision variables for the optimization problem of case two.

\begin{tabular}{ccccc}
\hline Parameter & CGO & WOA [29] & NNO [32] & GHO [23] \\
\hline$\xi_{1}(V)$ & -1.1053135621 & -0.8902 & -1.0596 & -1.1997 \\
$\xi_{2} \times 10^{-3}(V / K)$ & 3.506655471 & 3.3088 & 3.7435 & 4.2695 \\
$\xi_{3} \times 10^{-5}(V / K)$ & 6.726482341 & 9.75455 & 9.6902 & 9.8 \\
$\xi_{4} \times 10^{-5}(V / K)$ & -10.634713544 & -10.33 & -19.302 & -10.1371 \\
$\lambda$ & 21.517713112 & 22.8311 & 20.8772 & 23 \\
$R_{c}(\mathrm{~m} \Omega)$ & 0.272639115 & 0.5677 & 0.1 & 0.4638 \\
$\beta$ & 0.150008476 & 0.1464 & 0.0161 & 0.1486 \\
Population size & 50 & $\mathrm{NR}$ & $\mathrm{NR}$ & $\mathrm{NR}$ \\
Number of iterations & 2000 & 200 & $\mathrm{NR}$ & $\mathrm{NR}$ \\
Computation time $(\mathrm{s})$ & 116.798459 & 38.3 & 33 & 12.5 \\
SSE & 0.000142098 & 0.0111 & 0.0117 & 0.0478 \\
\hline
\end{tabular}

The internal voltage losses of the PEMFC of case two are plotted against the fuel cell current in Figure 14. In contrast to the case one fuel cell, the effect of $V_{\text {conc }}$ and $V_{\text {act }}$ on the total voltage losses is more observable. $V_{\text {conc }}$ increases nonlinearly at higher values of the fuel cell current. The ohmic losses has the minimum share in the total voltage losses. The simulations are repeated under different values of temperatures $\left(30^{\circ} \mathrm{C}, 50{ }^{\circ} \mathrm{C}\right.$, and $\left.70{ }^{\circ} \mathrm{C}\right)$ at constant partial pressures $\left(P_{\mathrm{H}_{2}} / P_{\mathrm{O}_{2}}=1.47 / 0.2 \mathrm{~atm}\right)$. The effects of changing the temperature on the output voltage and the output power are shown in Figures 15 and 16, respectively. It can be noted that the output voltage of the fuel cell increases upon the temperature rise. 


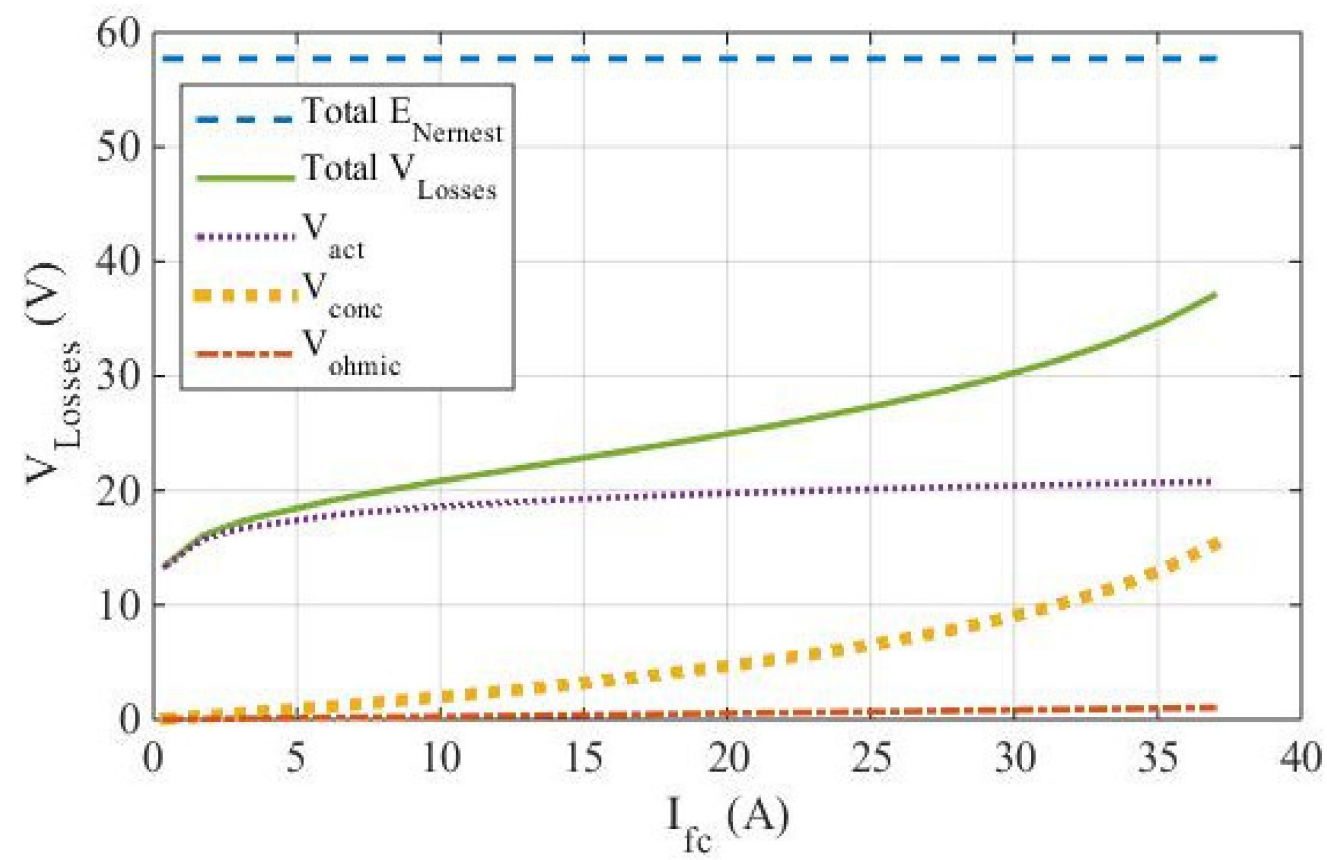

Figure 14. Internal voltage losses in case of AVISTA SR-12 $500 \mathrm{~W}$.

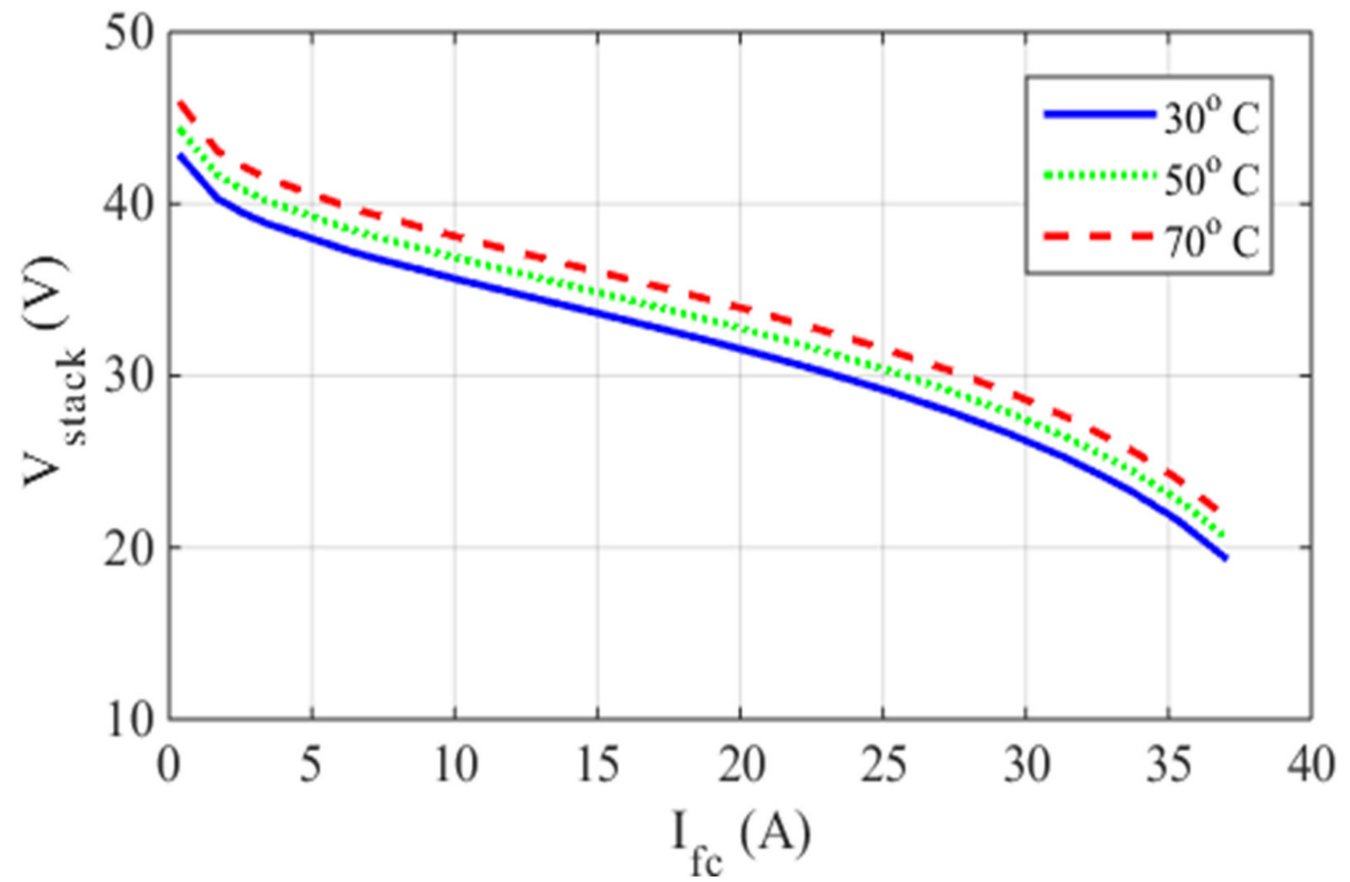

Figure 15. Comparison between I/V curves under various temperatures in case of AVISTA SR-12 $500 \mathrm{~W}$ PEMFC.

The simulations are further repeated at different pressures under constant temperature. This is done to test the effect of changing the pressure on the voltage. The effects of changing the pressure on the output voltage and the output power are shown in Figures 17 and 18. The voltage increases upon the increase in pressure.

\subsection{Case Three: The $6 \mathrm{~kW}$ Nedstack PS6}

The third considered PEMFC in this study is the $6 \mathrm{~kW}$ Nedstack PS6 PEMFC. The specifications of this PEMFC are provided in Table 4. The test is performed on 65 cells 
connected in series. The current passing through an area of $1 \mathrm{~cm}^{2}$ should not exceed $5 \mathrm{~A}$. The dimensions of the fuel cells under test are shown in the second and third rows in the table.

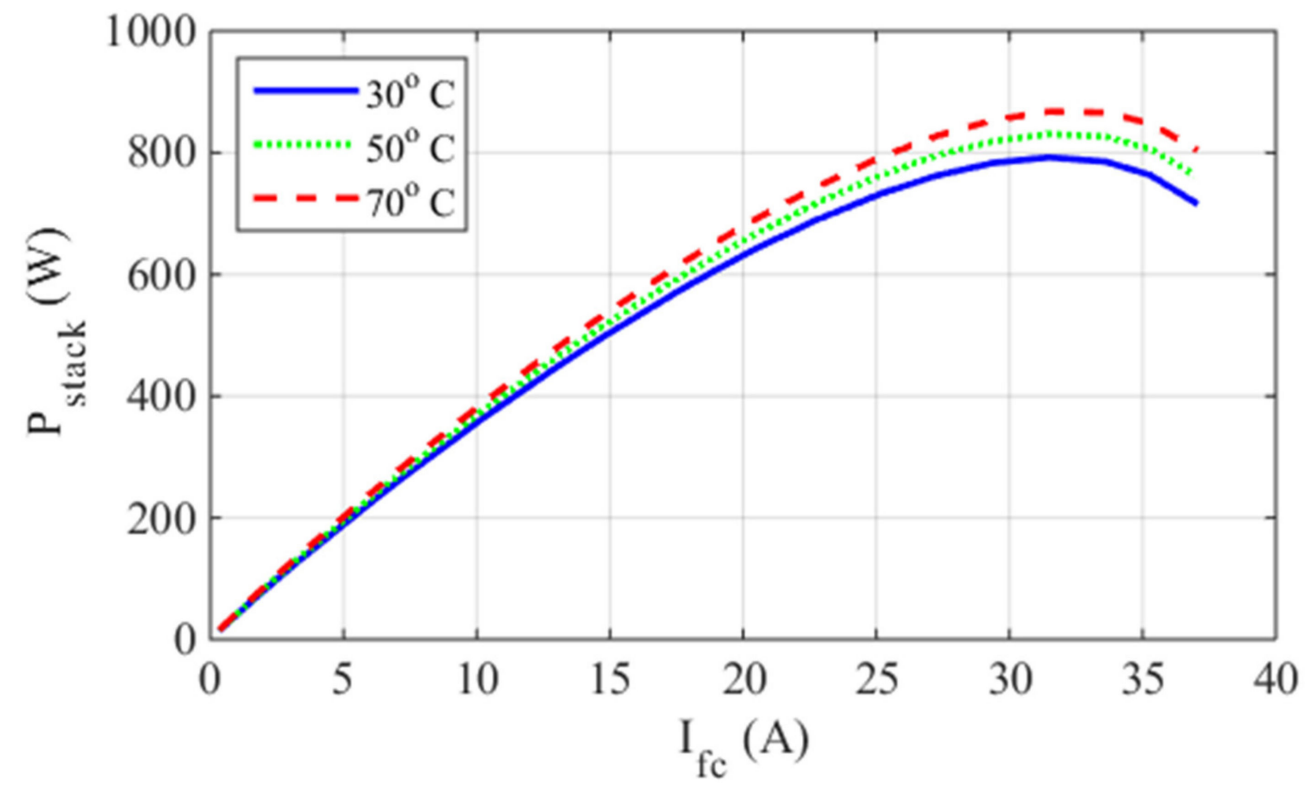

Figure 16. Comparison between I/P curves under various temperatures in case of AVISTA SR-12 500 W PEMFC.

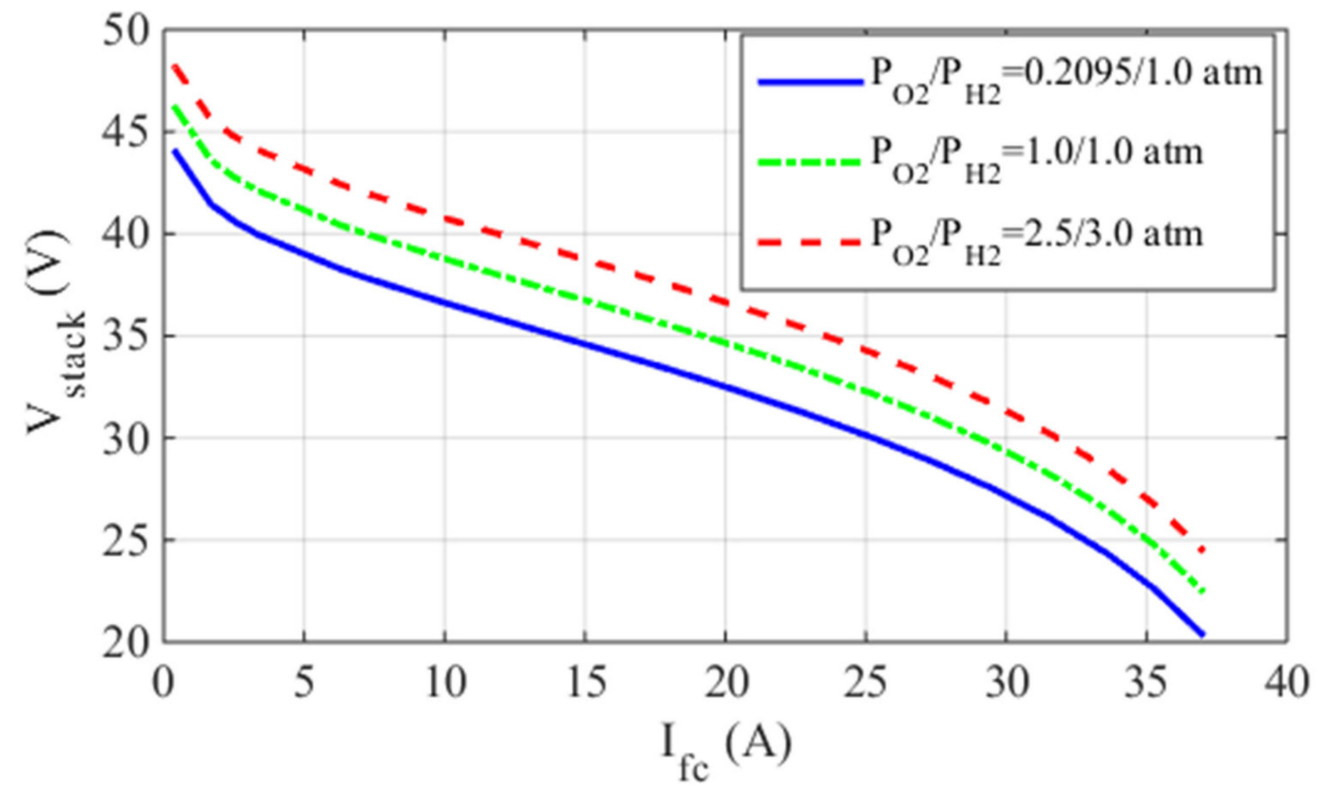

Figure 17. Comparison between I/V curves under various pressures in case of AVISTA SR-12 500 W PEMFC.

Table 4. Characteristics of PEMFC of case three.

\begin{tabular}{cc}
\hline Item & Value \\
\hline No. of series cells & 65 \\
Membrane thickness & $1.78 \mathrm{~mm}$ \\
Surface area $\left(M_{A}\right)$ & $240 \mathrm{~cm}^{2}$ \\
Max. current density & $5 \mathrm{~A} / \mathrm{cm}^{2}$ \\
\hline
\end{tabular}




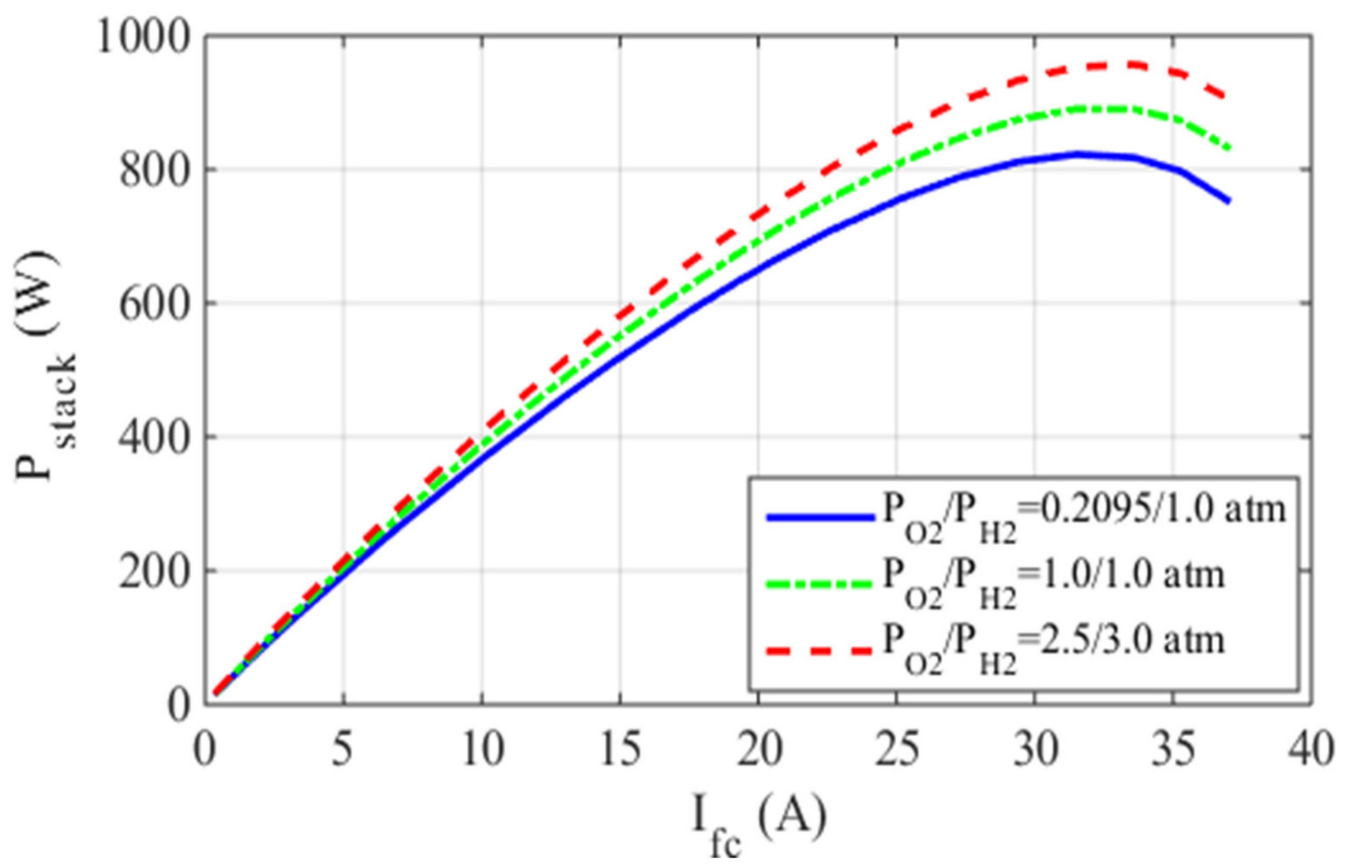

Figure 18. Comparison between I/P curves under various pressures in case of AVISTA SR-12 $500 \mathrm{~W}$ PEMFC.

Similar to the previous two cases, in Figure 19, the change in the values of the FF through the iterations can be seen. For further analysis, the I/V characteristics are provided in Figure 20. It shows a comparison between the estimated voltage and 29 samples of measured voltages. The fitting between the estimated and measured voltages is clear. The relationship between the current and the power is also provided in Figure 21.

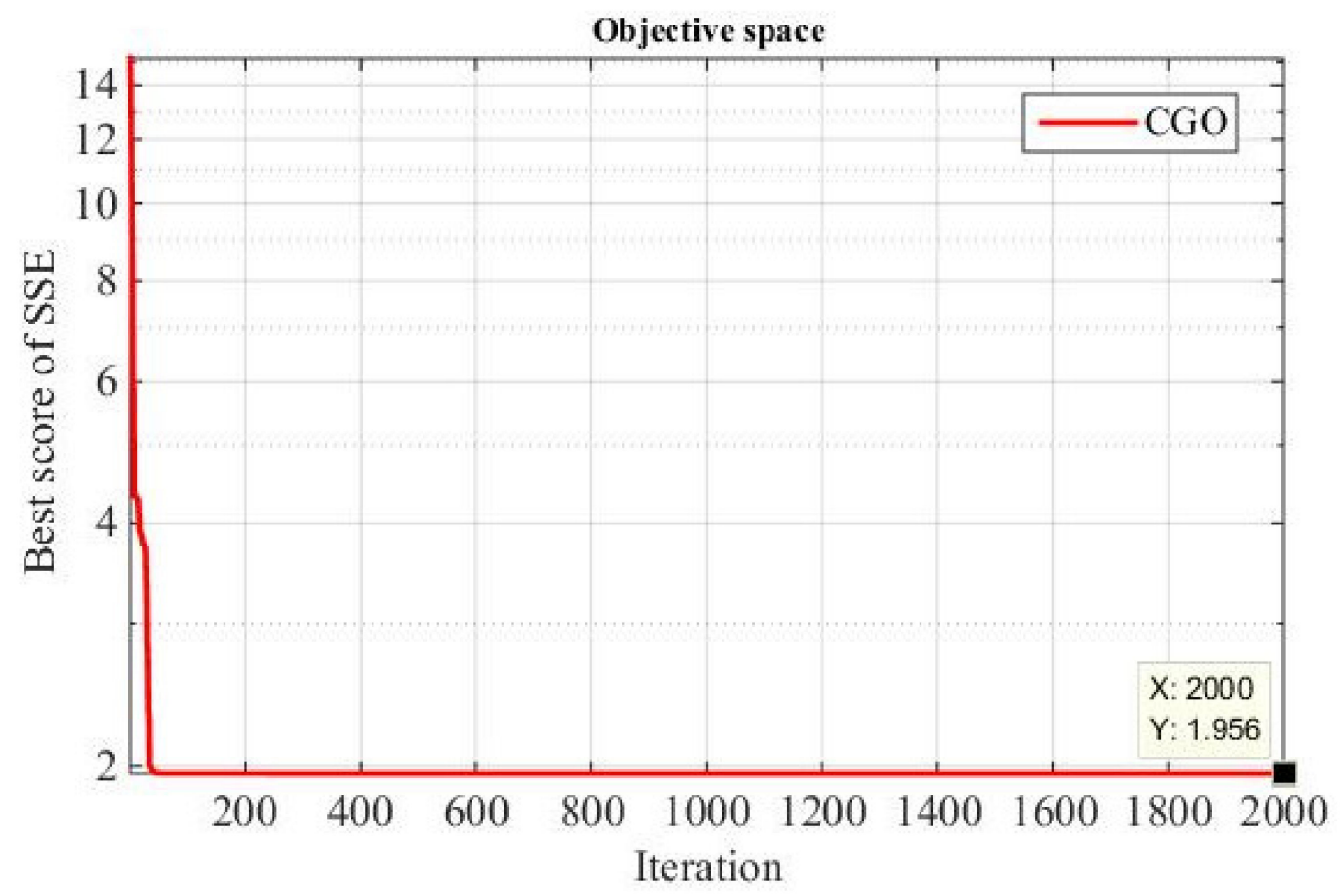

Figure 19. Convergence curve of the CGO method in case of $6 \mathrm{~kW}$ Nedstack PS6. 


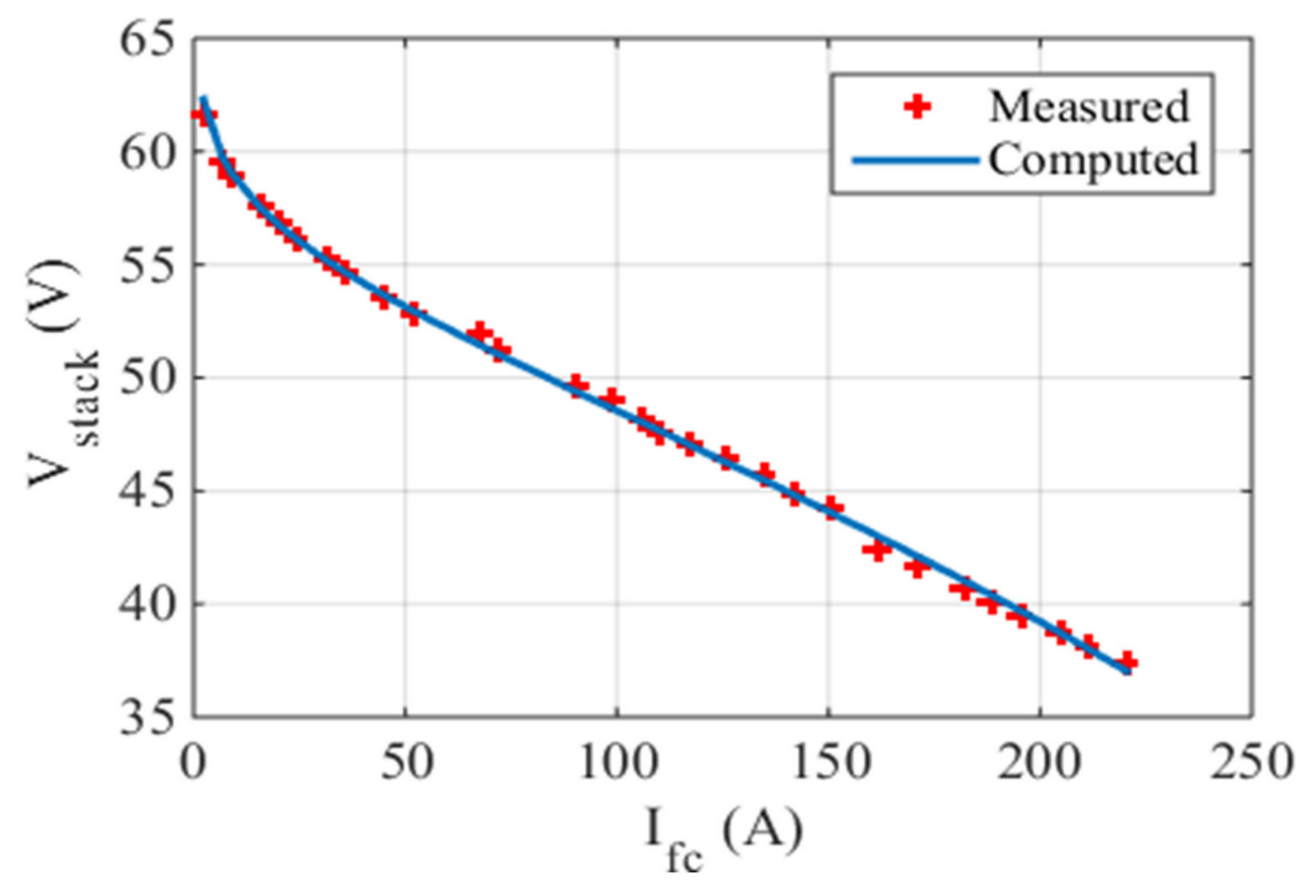

Figure 20. Comparison between estimated and practical current-voltage relationship of $6 \mathrm{~kW}$ Nedstack PS6.

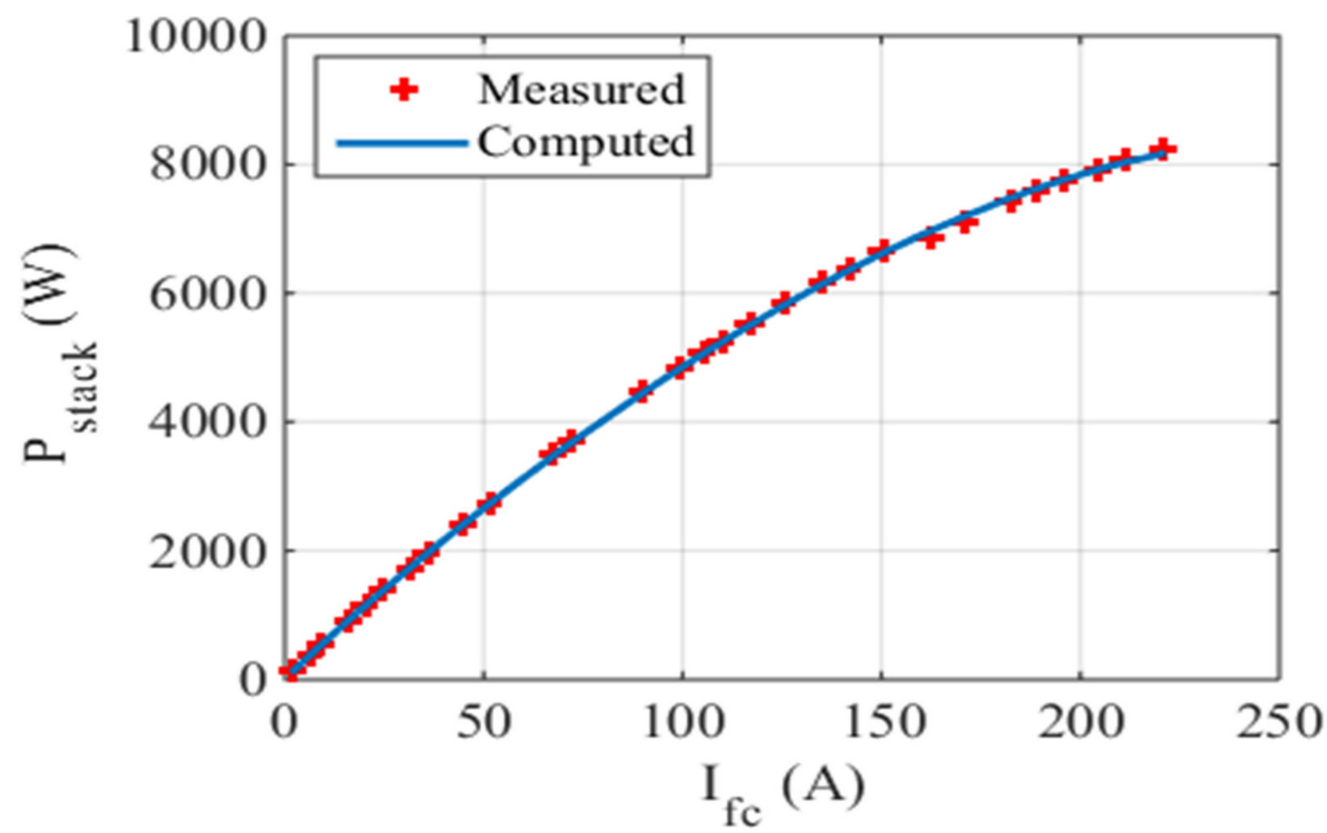

Figure 21. Comparison between estimated and practical current-power relationship of $6 \mathrm{~kW}$ Nedstack PS6.

Similar to results shown in Tables 2 and 3 of the first and second fuel cell cases, further comparisons between the newly developed CGO method versus WOA [29] and GHO [23] are presented in Table 5. They present the best candidate solutions of the design variables obtained by each optimization method, the best solution which corresponds to the minimum sum of the square of the errors between the calculated output voltages and the measured output voltages of the fuel cell, and the simulation time taken by each optimization method to finish the simulation and reach such results measured in seconds. 
Table 5. Decision variables for the optimization problem of case three.

\begin{tabular}{ccccc}
\hline Parameter & CGO & NNA [32] & SSO [21,25] & GA [23] \\
\hline$\xi_{1}(V)$ & -1.14692894516 & -0.8535 & -0.9719 & -1.1997 \\
$\xi_{2} \times 10^{-3}(V / K)$ & 3.27982148359 & 2.4316 & 3.3487 & 3.4172 \\
$\xi_{3} \times 10^{-5}(V / K)$ & 3.6043948463 & 3.7545 & 7.9111 & 3.6 \\
$\xi_{4} \times 10^{-5}(V / K)$ & -9.54 & -9.54 & -9.5435 & -9.54 \\
$\lambda$ & 13.013946837 & 13.0802 & 13 & 13 \\
$R_{c}(\mathrm{~m} \Omega)$ & 0.1 & 0.1 & 0.1 & 0.1376 \\
$\beta$ & 0.0136 & 0.0136 & 0.0534 & 0.0359 \\
Population size & 50 & $\mathrm{NR}$ & $\mathrm{NR}$ & $\mathrm{NR}$ \\
Number of iterations & 2000 & $\mathrm{NR}$ & $\mathrm{NR}$ & $\mathrm{NR}$ \\
Computation time $(\mathrm{s})$ & 91.7770779 & $\mathrm{NR}$ & $\mathrm{NR}$ & $\mathrm{NR}$ \\
$S S E$ & 1.955524791 & 2.14487 & 2.18067 & 2.4089 \\
\hline
\end{tabular}

The plot of the internal voltage losses is presented in Figure 22. As seen in this figure, $\mathrm{V}_{\text {act }}$ has the maximum effect on the total voltage losses. $V_{\text {ohmic }}$ has the second highest share in the total voltage losses. It increases almost linearly with the fuel cell current. $V_{\text {conc }}$ has a very small value, and it is an almost constant value which is independent of the fuel cell current. The simulations are done more than once under different temperatures $\left(30^{\circ} \mathrm{C}\right.$, $50{ }^{\circ} \mathrm{C}$, and $70{ }^{\circ} \mathrm{C}$ ) at constant partial pressures $\left(\mathrm{P}_{\mathrm{H}_{2}} / \mathrm{P}_{\mathrm{O}_{2}}=1 / 1 \mathrm{~atm}\right)$. The results of the investigation on the effect of changing the temperature are shown in Figures 23 and 24. The effect is that the voltage increases when the temperature rises. The difference in output voltage increases at higher values of current.

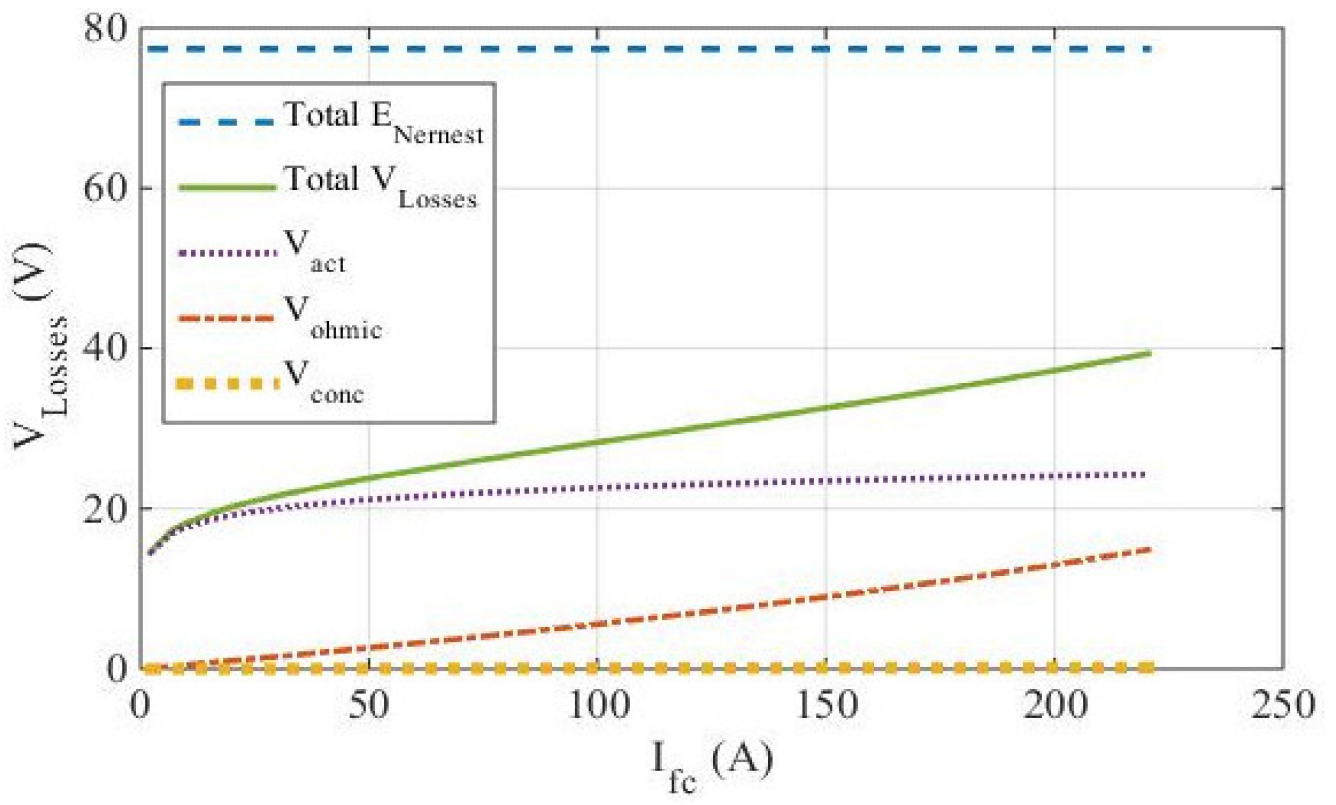

Figure 22. Internal voltage losses in case of $6 \mathrm{~kW}$ Nedstack PS6.

The simulations are also repeated under different pressures at constant temperature to measure the effect of tuning the pressure on the PEMFC voltage. The I/V curves are shown in Figures 25 and 26. From these two figures, it can be seen that the voltage increases when the pressure increases. After observing the results at different temperatures at constant pressure and vice versa, it is concluded that the effect of changing the temperature on the output voltage and the output power is higher than the effect of changing the pressure. 


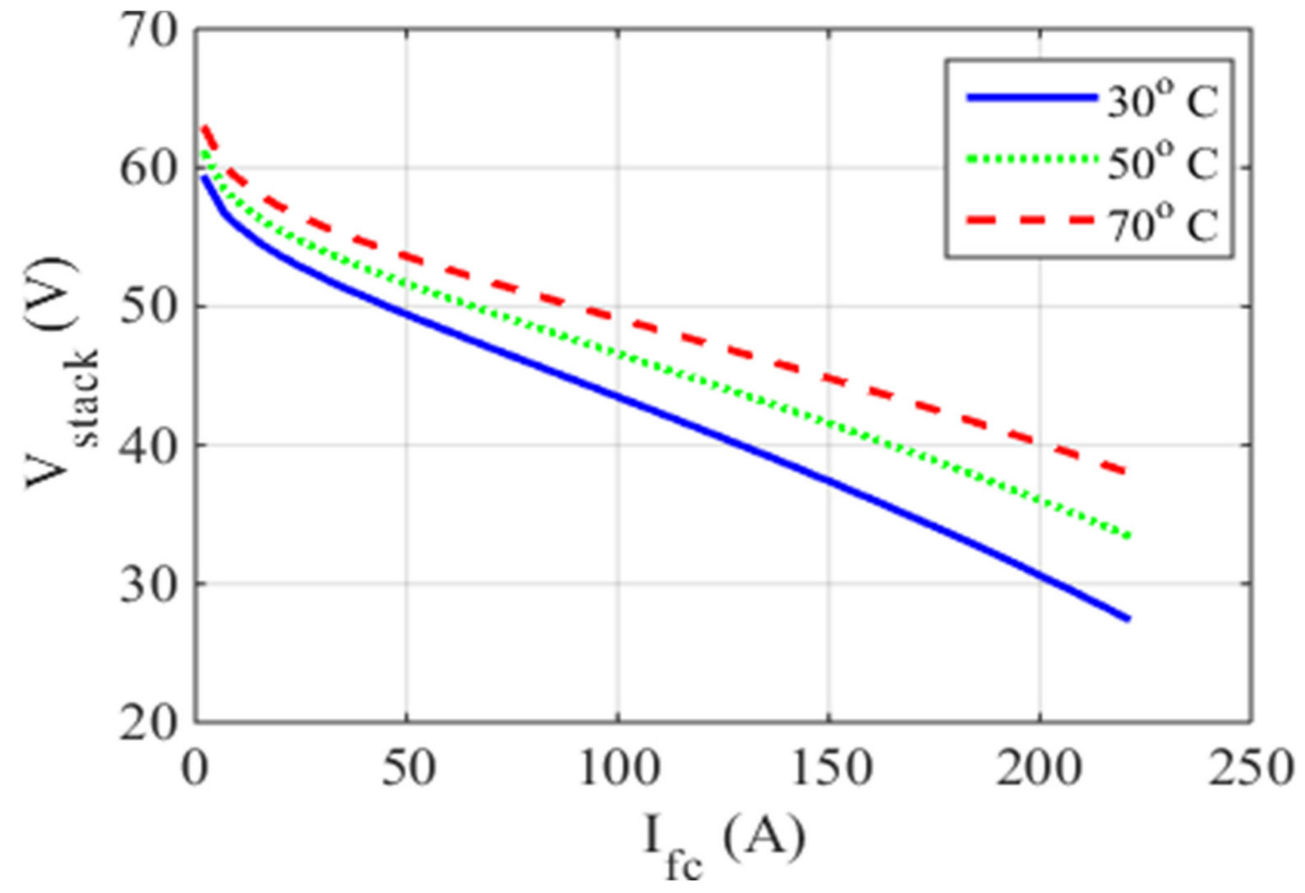

Figure 23. Comparison between I/V curves under various temperatures in case of $6 \mathrm{~kW}$ Nedstack PS6 PEMFC.

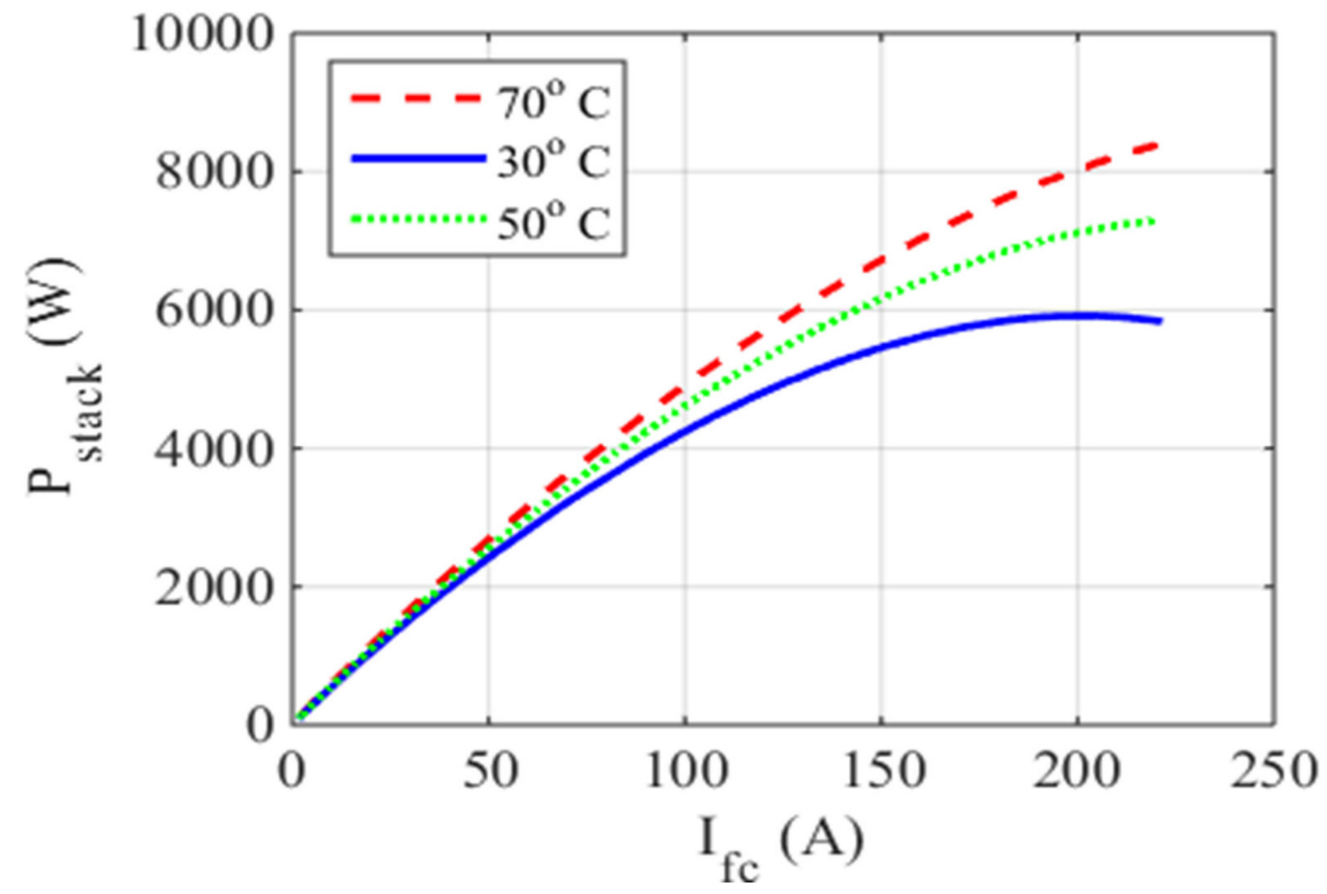

Figure 24. Comparison between I/P curves under various temperatures in case of $6 \mathrm{~kW}$ Nedstack PS6 PEMFC.

The proposed CGO managed to approximate the optimum values of the design variables of the PEMFCs and the constraints for lowest SSE. The superiority of the CGO PEMFC model reflects the high degree of performance of the CGO and an excellent architecture of the design. Moreover, it has a minimum number of factors and smooth convergence to the optimal solution.

The feasibility of the solution is evaluated by comparing the experimental results with the theoretical simulation results of three PEMFCs. The results achieved by other optimiza- 
tion methods confirmed the privilege of the CGO performance. The implementation of the CGO has resulted in a precise estimation of the PEMFC design variables.

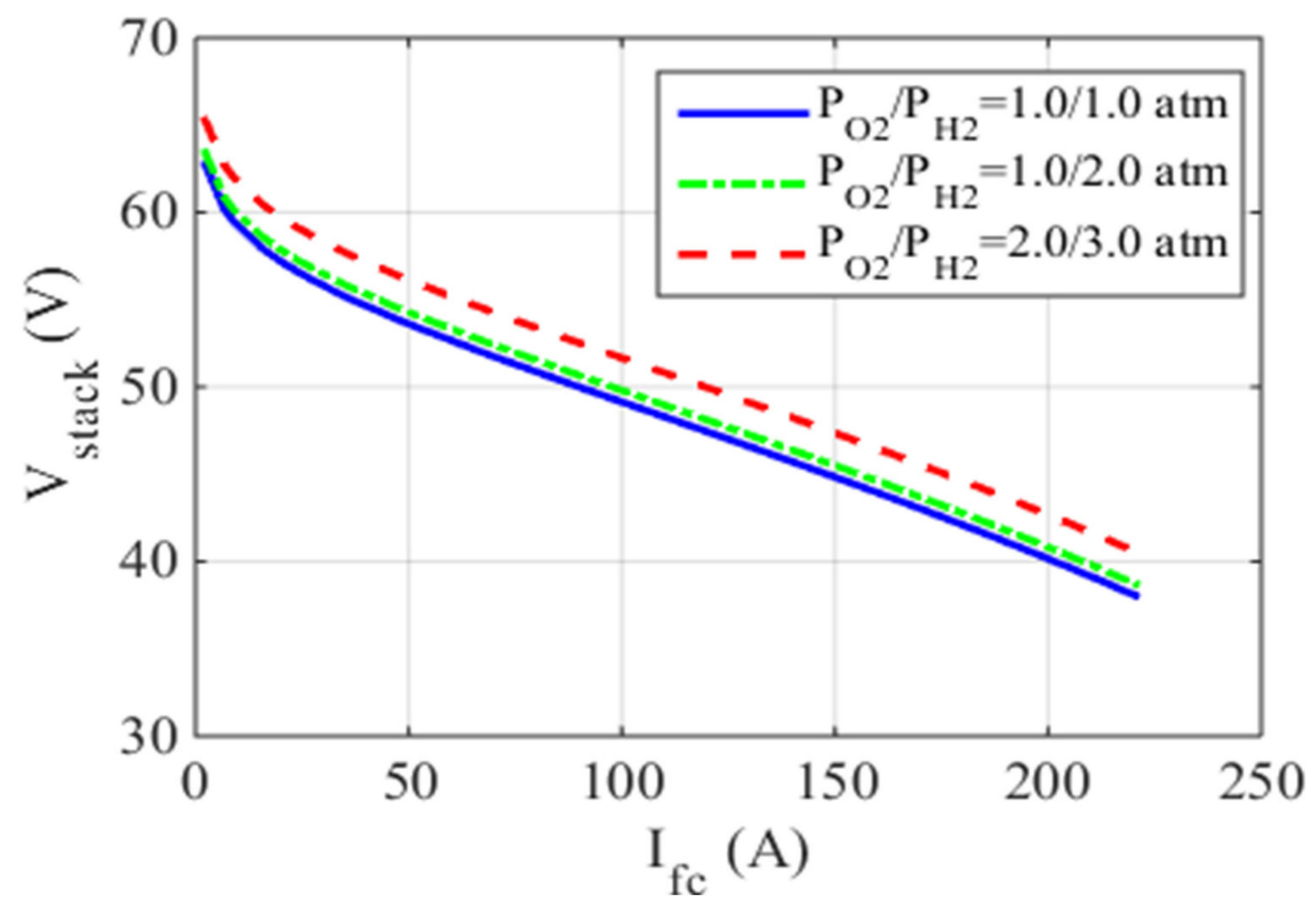

Figure 25. Comparison between I/V curves under various pressures in case of AVISTA SR-12 $500 \mathrm{~W}$ PEMFC.

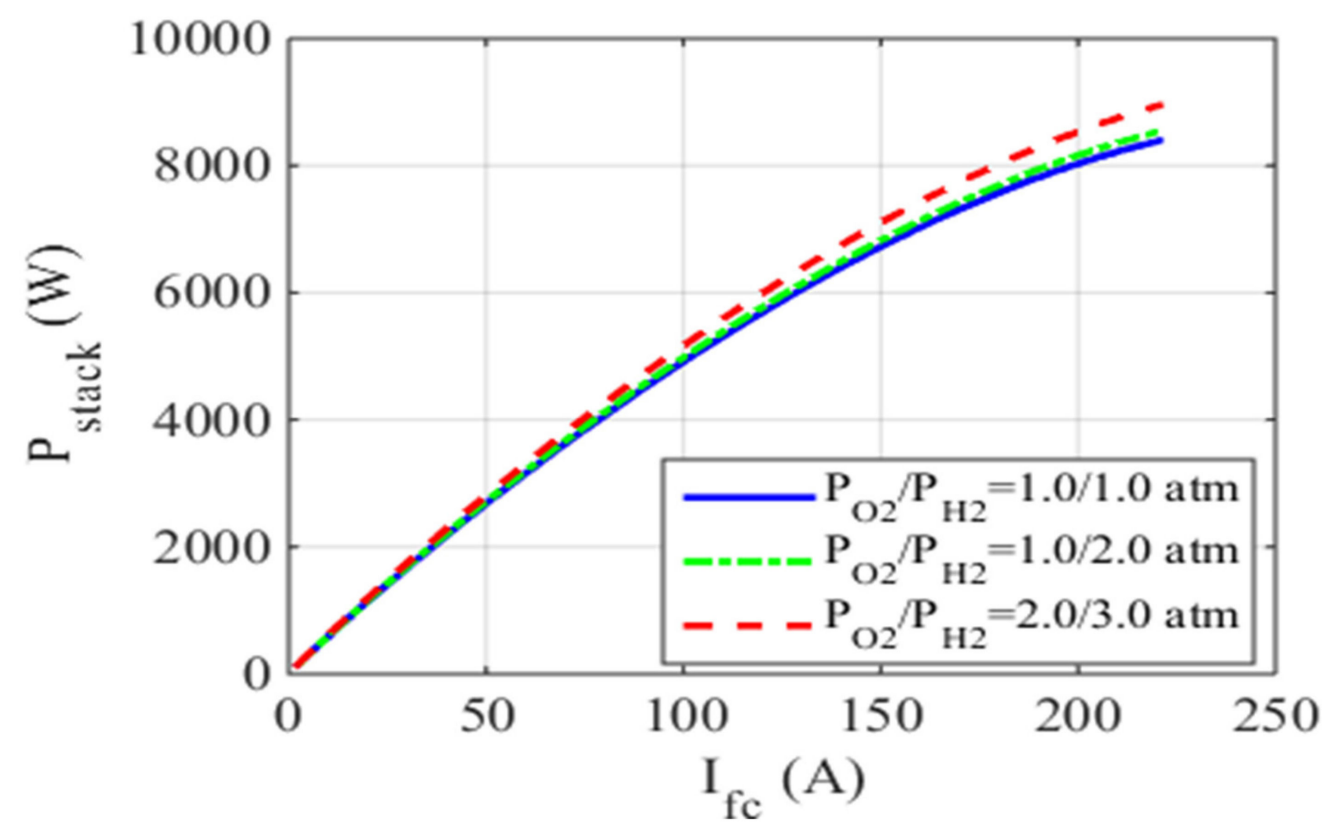

Figure 26. Comparison between I/P curves under various pressures in case of AVISTA SR-12 $500 \mathrm{~W}$ PEMFC.

\subsection{Robustness Statistical Analysis}

Many runs were conducted to further check the robustness of the CGO. The robustness of an optimization algorithm means that many runs should be performed of the same problem to assure that this method can reach such a solution at every run, and that the best 
solution is not obtained by chance at a single run. For each case, 30 independent runs were performed. The results of case one are shown in detail in Table 6.

Table 6. Statistical analysis of the proposed CGO algorithm.

\begin{tabular}{|c|c|}
\hline Run No. & Case One \\
\hline 1 & 0.853607516 \\
\hline 2 & 0.853607516 \\
\hline 3 & 0.853607516 \\
\hline 4 & 0.853607516 \\
\hline 5 & 0.853607516 \\
\hline 6 & 0.853607516 \\
\hline 7 & 0.853607516 \\
\hline 8 & 0.853607516 \\
\hline 9 & 0.853607516 \\
\hline 10 & 0.853607516 \\
\hline 11 & 0.853607516 \\
\hline 12 & 0.853607516 \\
\hline 13 & 0.853607516 \\
\hline 14 & 0.853607516 \\
\hline 15 & 0.853607516 \\
\hline 16 & 0.853607516 \\
\hline 17 & 0.853607516 \\
\hline 18 & 0.853607516 \\
\hline 19 & 0.853607516 \\
\hline 20 & 0.853607516 \\
\hline 21 & 1.087297383 \\
\hline 22 & 0.853607516 \\
\hline 23 & 0.853607516 \\
\hline 24 & 0.853607516 \\
\hline 25 & 0.853607516 \\
\hline 26 & 0.853607516 \\
\hline 27 & 0.853607516 \\
\hline 28 & 0.853607516 \\
\hline 29 & 0.853607516 \\
\hline 30 & 0.853607516 \\
\hline Max & 1.087297383 \\
\hline Median & 0.861397178 \\
\hline Min & 0.853607516 \\
\hline Standard Dev. & 0.042665737 \\
\hline Variance & 0.001820365 \\
\hline
\end{tabular}

The values of the standard deviation and the variance are low. This means that the results achieved by each run are very close to each other, indicating the robustness of the proposed optimization process.

\section{Conclusions}

This article proposed a novel attempt by the CGO to extract the design variables of the PEM fuel cell model. The goal is to achieve an effective PEMFC model that provides comprehensive simulation results for FCs. The FF is formulated to minimize the squaring error between the FC measured voltage and the calculated value. The CGO was introduced to minimize the FF under the problem constraints. The accuracy of the PEMFC model is proved under various temperature and pressure conditions. The efficiency of the constructed model is assessed by comparing the numerical model performance with the experimental results of the three commercial PEMFCs stacks tested. For all case studies, the simulation results coincided with the experimental outcomes. In comparison, the CGO results provided better results than the results based on alternative optimization approaches. This results in a high dominance in the literature of the CGO-based model over other models based on other optimization methods. The proposed CGO algorithm 
shall be used to solve several other engineering problems such as operation and control of microgrids and smart grids. In future work, the dynamic model of the PEMFCs can be considered instead of the static model. The aging factor of the fuel cell can be also considered.

Author Contributions: H.M.H. and I.A.—conceptualization and methodology; M.A.M.S.-software; M.A.- - validation, formal analysis, and investigation; A.S.A. and M.A.M.S.-resources, data curation, writing - original draft preparation; H.M.H. and I.A.—-review and editing, visualization, supervision, and project administration; and I.A.-funding acquisition. All authors have read and agreed to the published version of the manuscript.

Funding: This research was funded by Qassim University, represented by the Deanship of Scientific Research, with the financial support for this research under the number (10303-qec-2020-1-3-I) during the academic year $1441 \mathrm{AH} / 2020 \mathrm{AD}$.

Institutional Review Board Statement: Not applicable.

Informed Consent Statement: Not applicable.

Acknowledgments: The authors gratefully acknowledge Qassim University, represented by the Deanship of Scientific Research, for the financial support for this research under the number (10303qec-2020-1-3-I) during the academic year 1441 AH/2020 AD.

Conflicts of Interest: The authors declare no conflict of interest.

\author{
Abbreviations \\ CGO Chaos Game Optimization Algorithm \\ FC Fuel Cells \\ FF Fitness Function \\ NLOP Nonlinear Optimization Problem \\ PEMFC Proton Exchange Membrane Fuel Cell \\ SSE Sum of Squared Errors
}

\title{
References
}

1. Shen, J.; Zhengkai, T.; Siew, H.C. Evaluation criterion of different flow field patterns in a proton exchange membrane fuel cell. Energy Convers. Manag. 2020, 213, 112841. [CrossRef]

2. Hussien, A.M.; Mekhamer, S.F.; Hasanien, H.M. Cuttlefish Optimization Algorithm based Optimal PI Controller for Performance Enhancement of an Autonomous Operation of a DG System. In Proceedings of the 2020 2nd International Conference on Smart Power \& Internet Energy Systems (SPIES), Bangkok, Thailand, 15-18 September 2020.

3. Seleem, S.I.; Hasanien, H.M.; El-Fergany, A.A. El-Fergany. Equilibrium optimizer for parameter extraction of a fuel cell dynamic model. Renew. Energy 2021, 169, 117-128. [CrossRef]

4. Sohani, A.; Naderi, S.; Torabi, F.; Sayyaadi, H.; Akhlaghi, Y.G.; Zhao, X.; Talukdar, K.; Said, Z. Application based multi-objective performance optimization of a proton exchange membrane fuel cell. J. Clean. Prod. 2020, 252, 119567. [CrossRef]

5. Chen, H.; Liu, B.; Liu, R.; Weng, Q.; Zhang, T.; Pei, P. Optimal interval of air stoichiometry under different operating parameters and electrical load conditions of proton exchange membrane fuel cell. Energy Convers. Manag. 2020, 205, 112398. [CrossRef]

6. Agwa, A.M.; El-Fergany, A.A.; Sarhan, G.M. Steady-state modeling of fuel cells based on atom search optimizer. Energies 2019, 12, 1884. [CrossRef]

7. Kandidayeni, M.; Macias, A.; Khalatbarisoltani, A.; Boulon, L.; Kelouwani, S. Benchmark of proton exchange membrane fuel cell parameters extraction with metaheuristic optimization algorithms. Energy 2019, 183, 912-925. [CrossRef]

8. El-Hay, E.A.; El-Hameed, M.A.; El-Fergany, A.A. El-Fergany. Improved performance of PEM fuel cells stack feeding switched reluctance motor using multi-objective dragonfly optimizer. Neural Comput. Appl. 2019, 31, 6909-6924. [CrossRef]

9. Derbeli, M.; Barambones, O.; Farhat, M.; Ramos-Hernanz, J.A.; Sbita, L.; Derbeli, M.; Barambones, O.; Farhat, M.; Ramos-Hernanz, J.A.; Sbita, L. Robust high order sliding mode control for performance improvement of PEM fuel cell power systems. Int. J. Hydrog. Energy 2020, 45, 29222-29234. [CrossRef]

10. Karanfil, G. Importance and applications of DOE/optimization methods in PEM fuel cells: A review. Int. J. Energy Res. 2020, 44, 4-25. [CrossRef]

11. Gong, X.; Dong, F.; Mohamed, M.A.; Abdalla, O.M.; Ali, Z.M. A secured energy management architecture for smart hybrid microgrids considering PEM-fuel cell and electric vehicles. IEEE Access 2020, 8, 47807-47823. [CrossRef]

12. Fathy, A.; Elaziz, M.A.; Alharbi, A.G. A novel approach based on hybrid vortex search algorithm and differential evolution for identifying the optimal parameters of PEM fuel cell. Renew. Energy 2020, 146, 1833-1845. [CrossRef] 
13. Pan, M.; Li, C.; Liao, J.; Lei, H.; Pan, C.; Meng, X.; Huang, H. Design and modeling of PEM fuel cell based on different flow fields. Energy 2020, 207, 118331. [CrossRef]

14. Chugh, S.; Chaudhari, C.; Sonkar, K.; Sharma, A.; Kapur, G.; Ramakumar, S. Experimental and modelling studies of low temperature PEMFC performance. Int. J. Hydrog. Energy 2020, 45, 8866-8874. [CrossRef]

15. Taleb, M.A.; Béthouxb, O.B.; Godoy, E. Identification of a PEMFC fractional order model. Int. J. Hydrog. Energy 2017, 42, 1499-1509. [CrossRef]

16. Lyu, Z.; Meng, H.; Zhu, J.; Han, M.; Sun, Z.; Xue, H.; Zhao, Y.; Zhang, F. Comparison of off-gas utilization modes for solid oxide fuel cell stacks based on a semi-empirical parametric model. Appl. Energy 2020, 270, 115220. [CrossRef]

17. Geem, Z.W.; Noh, J.S. Parameter estimation for a proton exchange membrane fuel cell model using GRG technique. Fuel Cell 2016, 16, 640-645. [CrossRef]

18. Chavan, S.; Talange, D.B. Talange. Modeling and performance evaluation of PEM fuel cell by controlling its input parameters. Energy 2017, 138, 437-445. [CrossRef]

19. Rao, Y.; Shao, Z.; Ahangarnejad, A.H.; Gholamalizadeh, E.; Sobhani, B. Shark Smell Optimizer applied to identify the optimal parameters of the proton exchange membrane fuel cell model. Energy Convers. Manag. 2019, 182, 1-8. [CrossRef]

20. Priya, K.; Sathishkumar, K.; Rajasekar, N. A comprehensive review on parameter estimation techniques for Proton Exchange Membrane fuel cell modelling. Renew. Sustain. Energy Rev. 2018, 93, 121-144. [CrossRef]

21. Talatahari, S.; Azizi, M. Optimization of constrained mathematical and engineering design problems using chaos game optimization. Comput. Ind. Eng. 2020, 145, 106560. [CrossRef]

22. Mann, R.F.; Amphlett, J.C.; Hooper, M.A.I.; Jensen, H.M.; Peppley, B.A.; Roberge, P.R. Development and application of a generalised steady-state electrochemical model for a PEM fuel cell. J. Power Sources 2000, 86, 173-180. [CrossRef]

23. El-Fergany, A. Electrical characterisation of proton exchange membrane fuel cells stack using grasshopper optimiser. IET Renew. Power Gener. 2017, 12, 9-17. [CrossRef]

24. Saleh, I.M.M.; Ali, R.; Zhang, H. Simplified mathematical model of proton exchange membrane fuel cell based on horizon fuel cell stack. J. Mod. Power Syst. Clean Energy 2016, 4, 668-679. [CrossRef]

25. El-Fergany, A.A. Extracting optimal parameters of PEM fuel cells using salp swarm optimizer. Renew. Energy 2018, 119, 641-648. [CrossRef]

26. Talatahari, S.; Azar, B.F.; Sheikholeslami, R.; Gandomi, A. Imperialist competitive algorithm combined with chaos for global optimization. Commun. Nonlinear Sci. Numer. Simul. 2012, 17, 1312-1319. [CrossRef]

27. Shaheen, M.A.; Hasanien, H.M.; Alkuhayli, A. A novel hybrid GWO-PSO optimization technique for optimal reactive power dispatch problem solution. Ain Shams Eng. J. 2021, 12, 621-630. [CrossRef]

28. Shaheen, M.; Mekhamer, S.F.; Hasanien, H.M.; Talaat, H.E.A. Optimal Power Flow of Power Systems Using Hybrid Firefly and Particle Swarm Optimization Technique. In Proceedings of the 2019 21st International Middle East Power Systems Conference (MEPCON), Cairo, Egypt, 17-19 December 2019; pp. 232-237.

29. El-Fergany, A.A.; Hasanien, H.M.; Agwa, A.M. Semi-empirical PEM fuel cells model using whale optimization algorithm. Energy Convers. Manag. 2019, 201, 112197. [CrossRef]

30. Zhang, G.; Jiao, K. Three-dimensional multi-phase simulation of PEMFC at high current density utilizing Eulerian-Eulerian model and two-fluid model. Energy Convers. Manag. 2018, 176, 409-421. [CrossRef]

31. Qais, M.H.; Hasanien, H.M.; Alghuwainem, S. Transient search optimization: A new meta-heuristic optimization algorithm. Appl. Intell. 2020, 50, 3926-3941. [CrossRef]

32. Fawzi, M.; El-Fergany, A.A.; Hasanien, H.M. Hasanien. Effective methodology based on neural network optimizer for extracting model parameters of PEM fuel cells. Int. J. Energy Res. 2019, 43, 8136-8147. [CrossRef] 